\title{
BETWEEN-FIRM REDISTRIBUTION OF PROFIT IN COMPETITIVE INDUSTRIES: WHY LABOR MARKET POLICIES MAY NOT WORK
}

\section{Galina Vereshchagina}
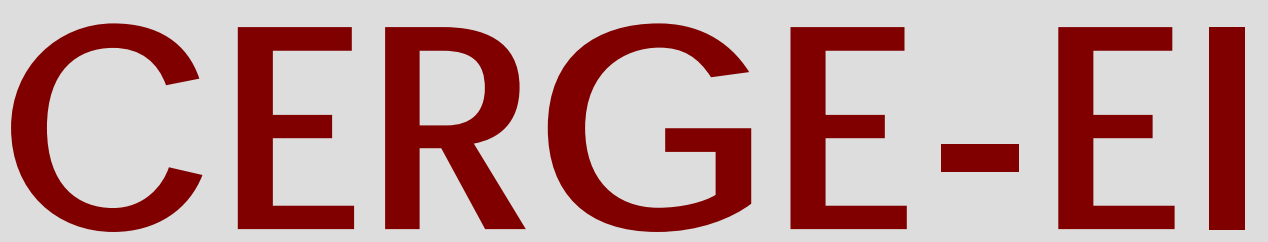

Charles University CenterforEconomic Research and Graduate Education Academy of Sciences of the Czech Republic Ec onomic s Institute 


\section{Working Paper Series \\ 268 (ISSN 1211-3298)}

\section{Between-Firm Redistribution of Profit in Competitive Industries: Why Labor Market Policies May Not Work}

Galina Vereshchagina

CERGE-EI

Prague, August 2005 
ISBN 80-7343-061-4 (Univerzita Karlova v Praze, CERGE)

ISBN 80-7344-050-4 (Národohospodářský ústav AV ČR, Praha) 


\title{
Between-Firm Redistribution of Profit in Competitive Industries: Why Labor Market Policies May Not Work*
}

\author{
Galina Vereshchagina ${ }^{\dagger}$
}

June 2005

\begin{abstract}
Empirical studies document differences in firms' response to the introduction of various labor market policies. In particular, large and mature firms tend to participate more actively in targeted employment subsidy programs (under which firms receive subsidies for hiring disadvantaged workers). This paper offers an explanation for this phenomenon and argues that it might have important consequences for policy making.

Namely, such behavior of firms may indicate that large and mature firms benefit from the introduction of a new subsidy program, while small and young firms incur indirect costs. In this case, the policy implicitly redistributes profit from young to mature firms and may discourage startups if the entry into the industry is competitive. The resulting decrease in the number of operating firms is likely to have a significant impact on the policy's outcomes. These effects become more pronounced as heterogeneity between young and mature firms increases.
\end{abstract}

\begin{abstract}
Abstrakt
Empirické studie dokumentují rozdíly v reakci podniků na zavedení různých nástrojú trhu práce. Velké a etablované podniky mají vyšší tendenci se aktivně podílet na programech dotovaného zaměstnávání (při kterém podniky dostávají dotace pro zaměstnávání znevýhodněných pracovníků) Tato studie nabízí vysvětlení tohoto fenoménu a argumentuje, že tento fenomén může mít významné dopady na politiku pracovního trhu.

Konkrétně, tato reakce podniků může poukazovat na to, že velké a etablované podniky benefitují ze zavedení nových dotačních programů, kdežto malé a začínající podniky na tyto programy nepřímým způsobem doplácejí. V takovémto případě tyto programy implicitně redistribují zisky od začínajících k etablovaným podnikům a můžou odradit vznik nových podniků v př́pade, že vstup do oboru podnikání je neomezený. Následný pokles v počtu aktivních podniků tak zřejmě má významný vliv na výsledný efekt těchto programů. Význam těchto efektů roste s narůstající heterogenitou mezi začínajícími a etablovanými podniky.
\end{abstract}

\footnotetext{
* I am grateful to Radim Bohacek and Sergey Slobodyan for useful suggestions and remarks. This research was supported by a grant from CERGE-EI Foundation under a program of the Global Development Network. All opinions expressed are those of the author and have not been endorsed by CERGE-EI, WIIW, or the GDN.

${ }^{\dagger}$ Contact address: Department of Economics, University of Iowa, 21 E Market St, Iowa City, IA 52242. Email: galina-vereshchagina@uiowa.edu.
} 


\section{Introduction}

In economies with substantial firm heterogeneity, some firms may incur losses while others may benefit as a result of a new labor market policy introduced by the government. In other words, the policy may redistribute profits among different groups of firms. This paper argues that such redistribution may have important implications for policymaking if (i) entry into the industry is competitive and (ii) there are substantial differences in size or productivity between young and mature firms. In particular, if mature firms are the ones who, for some reason, benefit from the introduction of a labor market policy, the expected lifetime profit of entrants may decrease, thereby discouraging start-ups and reducing the number of operating firms. Naturally, the resulting decline in the size of the production sector might have important implications for policy analysis.

For example, a government may introduce an employment subsidy program aimed at increasing an economy's total employment level. While designing this program, a policymaker may believe that either the policy would have no impact on the number of firms operating in the economy or that it would affect entrants as much as mature firms. Relying on these assumptions, the policymaker would expect that the new subsidy program would reduce the economy's unemployment level. However, this paper presents a theory and a numerical example illustrating that the opposite may happen after the policy is implemented, due to the adverse effect on total employment caused by a massive exit of firms.

This study focuses on the effects of the employment subsidies paid to firms hiring workers with particular characteristics (e.g., having relatively low skills, being long term unemployed). Even though such policy is primarily targeted to a special group of workers, it also implicitly favors those firms who either create relatively more jobs for the workers from the targeted group or appear to be more responsive to a decrease in these workers' labor cost.

Several versions of such targeted employment subsidy programs have been used by policymakers in different countries during the last decade. ${ }^{1}$ Availability of data about the participants in these subsidy programs stimulated a large number of empirical studies evaluating their outcomes. Some of these works focus on the labor market perspectives of the targeted group of workers, others study displacement effects and potential

\footnotetext{
${ }^{1}$ Examples of such policies include Targeted Job Tax Credit in the U.S., New Deal in Britain, various wage subsidies in Canada and Sweden, etc.
} 
deadweight losses, several more focus on the subsidies' effects on aggregate employment in a particular sector. ${ }^{2}$ At the same time, there is no unanimous agreement regarding the success of these subsidy programs because empirical evidence is quite controversial and depends on the program's setup, its scale, size of the targeted group and many other factors. In contributing to the existing literature, this paper suggests that the heterogeneity between young and mature firms might serve as a potential explanatory variable in the empirical analysis evaluating the targeted employment subsidy programs. The theory developed in this study predicts that, in competitive industries, the bigger the differences between young and mature firms, the more likely it is that the subsidy program will not be successful.

Despite much attention that the existing theoretical literature has paid to understanding the impacts of various labor market policies and identifying the important mechanisms responsible for the policies' outcomes, there has not been, to my knowledge, any study focusing primarily on the role of between-firm redistribution driven by the introduction of a new policy. A possible reason for such a gap in the literature is that in many cases the assumptions used in theoretical models do not allow for the full accounting of the relationship between this redistribution effect and the number of firms operating in the economy. For example, some studies explicitly assume that the number of firms in the industry is fixed at an exogenously given level and cannot change in response to the introduction of a new policy. ${ }^{3}$ Another class of models allows for the pinning down of the number of firms endogenously, but relies on the assumption that the entrants are no different from the mature firms, thereby neglecting the potential effect that redistribution of profits among firms with different characteristics may have on the number of firms in the economy. ${ }^{4}$

A different approach is taken in the work by Hopenhayn and Rogerson (1993), in which the impacts of firing taxes are analyzed in the context of an industry dynamics framework with heterogeneous firms and endogenous entry and exit flows. Their paper draws attention to the welfare implications of the firing taxation program as well as its impact on the productivity of entering and surviving firms. At the same time, it neither describes the redistributionary effects of the policy nor points out their potential

\footnotetext{
${ }^{2}$ See, for example, Bishop and Montgomery (1986), Hollenbeck and Willke (1991), Katz (1996), Bell, Blundell and Van Reen (1999), Blundell and Meghir (2001), Calmfors, Forslund and Hemstrom (2001), Martin and Grebb (2001), Sianesi (2001) and many others.

${ }^{3}$ See, for example Alvarez and Veracierto (2000), Richardson (1997), etc.

${ }^{4}$ In Mortensen and Pissarides (1998) the number of vacancies is determined endogenously, but it is assumed that entrants draw a productivity shock from the same distribution as older firms do.
} 
importance for policy analysis. That is why in the current paper I modify Hopenhayn and Rogerson's (1993) framework and use it to study the response of the economy to the introduction of a targeted employment subsidy program. The goal of this exercise is to identify the role of between-firm redistribution in explaining some of the policy's outcomes.

The theoretical framework developed in this paper is based on a simple model of industry equilibrium with heterogeneity on both sides of the labor market. Firms differ in their size and age, which are positively related to each other. As in Hopenhayn (1992), entry into the industry is competitive, so in the equilibrium the value of entrants, measured as their expected discounted life-time flow of profit, is equal to the cost of starting a new enterprize. Workers have different skills, and low-skilled workers ought to receive additional training before starting their job. For this reason, in the equilibrium low-skilled workers receive lower wage and have higher unemployment rates than highskilled workers do.

Firms incur a cost for training unskilled employees. Empirical evidence suggests that larger firms tend to provide more training per employed worker ${ }^{5}$ as well as to participate more actively in the subsidy programs. ${ }^{6}$ These implications endogenously arise in the model if the training cost function is convex in the fraction of firms' unskilled employees. Intuitively, if firms' production technology is concave, the convexity of the training cost is easily derived from the assumption that skilled workers have to spend some of their working time training their unskilled colleagues rather than producing. In reality, firms report that much of the training they provide is indeed done in this way. ${ }^{7}$

Another implication of the training cost's convexity explains why the government might consider employment subsidies for hiring unskilled workers as a good policy instrument aimed at increasing total employment. The model predicts that, in response to a decrease in the wage of unskilled workers, every operating firm not only decides to hire more unskilled employees, but also creates more jobs for skilled workers. Intuitively, if a firm hires more employees requiring additional training, it must also hire more workers, who are able to provide training services, otherwise training all new unskilled hires becomes too expensive. Such complementarity in the workers' types gives the hope

\footnotetext{
${ }^{5}$ For instance, see the data from the 1995 Survey of Employer-Provided Training collected by the Bureau of Labor Statistics (Sept95).

${ }^{6}$ For evidence, see Bishop and Montgomery (1986).

${ }^{7}$ In the Sept95 survey, firms report that over 70 percent of training is usually delivered through informal instructions rather than officially organized classes.
} 
that subsidizing unskilled workers would stimulate demand for both types of labor and, consequently, would raise aggregate employment.

The above argument would be correct if the number of firms in the economy were not affected by the subsidy program. However, if the number of operating firms is determined endogenously, the subsidy could induce some firms to exit and the total unemployment could rise. For example, a calibrated numerical exercise shows that if $30 \%$ of unskilled workers' wages are subsidized by the government, the aggregate unemployment rate falls from $6 \%$ to $3.4 \%$ in an economy with a constant number of firms. On the other hand, the same subsidy program increases unemployment from $6 \%$ to $6.7 \%$ if the number of firms is determined endogenously.

In general, exit of firms from the economy could occur for two reasons: either because the subsidy program redistributes profit from entrants to mature firms or because the subsidy expenditures are financed by a distortionary tax. That is why, in order to illustrate the importance of the former redistributionary effect, the second part of the numerical exercise compares the calibrated benchmark economy, in which entrants are $68 \%$ smaller than incumbent firms, with the economy where the entrants are only $41 \%$ smaller than the incumbents. In the absence of subsidies, the equilibrium allocations in the two economies are identical. However, if the same subsidy program is implemented in both economies, fewer firms exit from the economy with relatively large entrants, and, therefore, the resulting equilibrium unemployment rate is higher in the economy with more heterogeneity between young and mature firms. In particular, the $30 \%$ subsidy, which induces the unemployment rate to rise to $6.7 \%$ in the benchmark economy, reduces unemployment to $4.7 \%$ in the modified economy with larger entrants.

The remaining of the paper is organized as follows. Section 2 describes firms' decision in a partial equilibrium framework, explains in details why and how the redistribution effect may occur and derives the aggregate economy's demand for both types of labor. Section 3 describes how the equilibrium allocation in the economy is determined and argues that accounting for endogeneity of the number of firms is likely to have an important effect. Section 4 describes the calibration technique and summarizes the results of numerical policy experiments. Section 5 outlines the main findings of the paper and comments on some of the assumptions made in the theoretical model. 


\section{Firms' Hiring Decision}

This section characterizes the employment decision of firms in a partial equilibrium framework. It shows that, under the assumption of a convex training cost, large firms, as compared to the small ones, hire more unskilled labor, incur higher training expenditures and, correspondingly, benefit more from the introduction of targeted employment subsidies. This is done in two steps. First, I describe the hiring policies of firms in a static setup and analyze the effects of employment subsidies on one-period firms' profits. Then I show that static results can be extended to a dynamic setting. The last part of this Section describes the aggregate firm dynamics, derives the economy's demand for both types of labor and discusses why the introduction of targeted employment subsidies may affect the total number of firms in the economy.

\subsection{The effect of targeted employment subsidies on firms' cur- rent profit}

Consider an economy in which there are two types of workers, skilled and unskilled. Only skilled employees can be productively working in a firm. That is why if a firm hires unskilled workers it must provide them with a certain amount of training. Training is costly. Firms' training cost rises with the number $n_{l}$ of unskilled hires and falls with the amount $n_{h}$ of skilled employees. Without loss of generality, it is assumed that the training cost can be represented as a function of the fraction of unskilled to skilled employees, $n_{l} / n_{h}$. It is also assumed that the training cost is convex in $n_{l} / n_{h}$ :

$$
c\left(\frac{n_{l}}{n_{h}}\right)=\left(\frac{n_{l}}{A n_{h}}\right)^{1+\gamma},
$$

where $A>0$ and $\gamma>0$ for all $n_{h}>0$ and $n_{l}>0$. As it is shown later, the assumption of convexity allows us to obtain a positive relationship between the firm size and the amount of training provided by the firm, which is observed in the data. ${ }^{8}$

Given this cost function and the wages $w_{h}$ and $w_{l}$ paid to skilled and unskilled

\footnotetext{
${ }^{8}$ In a more general case, these properties of the cost function $c\left(n_{h}, n_{l}\right)$ could be derived endogenously under the assumption that skilled employees have to spend some of their working time training their unskilled colleagues. Assuming that $\lambda$ units of time are required to train one worker, one can easily show that the endogenous cost of hiring arising in this environment satisfies the following conditions for some $\bar{\lambda}<1$ and all $\lambda>\bar{\lambda}$ : $\widetilde{c}_{1}\left(n_{h}, n_{l}\right)<0, \widetilde{c}_{2}\left(n_{h}, n_{l}\right)>0, \widetilde{c}_{11}\left(n_{h}, n_{l}\right)>0, \widetilde{c}_{12}\left(n_{h}, n_{l}\right)<0$, and $\widetilde{c}_{22}\left(n_{h}, n_{l}\right)>0$. It is straightforward to verify that similar properties hold for the cost function determined by (1).
} 
workers respectively, every firm decides how many employees of each type it wants to hire. The hiring decision is made at the very beginning of the period, then training is provided for unskilled workers, and after that production takes place. Since unskilled workers become identical to skilled employees after the former receive necessary training, firms' output can be expressed as a function of total employment $l=n_{h}+n_{l}$. The production technology is given by $s f(l)=l^{\alpha}$, where $\alpha \in(0,1)$ and $s \in[0, \bar{s}]$ is a firm productivity level. ${ }^{9}$ Productivity is random and follows the Markov process with the conditional distribution given by $Q\left(s^{\prime} \mid s\right)$.

For simplicity, it is assumed that firms face no fixed production cost, thus instantaneous profit of a firm having productivity shock $s$ and hiring $n_{h}$ and $n_{l}$ workers of each type is given by

$$
\pi\left(s, n_{h}, n_{l} ; w_{h}, w_{l}\right)=s f\left(n_{h}+n_{l}\right)-w_{h} n_{h}-w_{l} n_{l}-c\left(n_{l} / n_{h}\right)
$$

Note that, due to the absence of a fixed cost, a firm hiring no workers produces no output and pays no cost, so its profit is equal to zero, $\pi(s, 0,0)=0$.

The optimal hiring policies $n_{h}^{*}\left(s ; w_{h}, w_{l}\right)$ and $n_{l}^{*}\left(s ; w_{h}, w_{l}\right)$ are derived in a simple profit maximization problem:

$$
\pi^{*}\left(s ; w_{h}, w_{l}\right)=\max _{n_{h}, n_{l}}\left\{\pi\left(s, n_{h}, n_{l} ; w_{h}, w_{l}\right)\right\}
$$

The following Lemma describes the properties of the firms' hiring decision.

Lemma 1 If $f(l)=l^{\alpha}$, the training cost function $c(\cdot)$ is given by (1) and $w_{h}>w_{l}$. Assume also that the following condition is satisfied:

$$
\gamma>\left(1-\frac{w_{h}}{w_{l}}\right) \frac{|2 \alpha-1|}{1-\alpha}
$$

Then

(i) for every $s>0$, there exists a unique bundle of hiring policies $n_{h}^{*}\left(s ; w_{h}, w_{l}\right)>0$ and $n_{l}^{*}\left(s ; w_{h}, w_{l}\right)>0$, which solves (2);

(ii) total employment $l^{*}\left(s ; w_{h}, w_{l}\right)=n_{h}^{*}\left(s ; w_{h}, w_{l}\right)+n_{l}^{*}\left(s ; w_{h}, w_{l}\right)$ as well as the fraction

\footnotetext{
${ }^{9}$ In general, most of the paper's results hold if certain conditions are imposed on the curvature on the production function $f(l)$ and on the degree of convexity of the training cost function $(\gamma$ should be large enough). However, adopting the functional form $f(l)=l^{\alpha}$ allows us to derive simple sufficient conditions for existence and uniqueness of firms' decision and thus turns out to be very handy.
} 
of unskilled employees $n_{l}^{*}\left(s ; w_{h}, w_{l}\right) / l^{*}\left(s ; w_{h}, w_{l}\right)$ are increasing in firms' productivity level s.

(iii) $\left|\partial \pi^{*}\left(s ; w_{h}, w_{l}\right) / \partial w_{l}\right|$ is increasing in $s$, i.e., the instantaneous profit of more productive firms is more sensitive to the changes in the wage of unskilled workers;

(iv) $\lim _{s \rightarrow 0} \frac{\pi^{*}\left(s ; w_{h}, w_{l}-\Delta\right)}{\pi^{*}\left(s ; w_{h}, w_{l}\right)}=1$ for all $\Delta>0$.

The proofs of this Lemma and of all the following results are given in the Appendix in the end of the paper.

The first statement of the above Lemma simply says that the maximization problem (2) always has a unique solution. The second statement allows for a comparison of the predictions of the model with the data. It states that the firms with higher productivity shocks hire more workers, therefore they will be further referred to as large firms. The second statement also claims that the relative quantity of unskilled employees is higher in large firms. Knowing this, it is straightforward to see that the fraction of labor cost spent on the salary of unskilled workers as well as expenditures on training firms' own employees are higher in larger firms. This is where the convexity of the training cost function plays its role: given the specification of the model, it would be hard to derive these regularities that are observed in the data without this assumption.

Intuitively, this result can be explained by comparing the marginal benefit and the marginal cost arising due to an increase in the fraction $n_{l} / l$ of a firm's unskilled employees. Due to lower wage cost, the firm's total benefit is proportionate to the number of its unskilled employees $\left(w_{h}-w_{l}\right) n_{l}$. Thus the marginal benefit from increasing the fraction of unskilled workers is proportionate to the total number of the firm's employees $\partial\left(\left(w_{h}-w_{l}\right) n_{l}\right) / \partial\left(n_{l} / l\right)=\left(w_{h}-w_{l}\right) l$. At the same time, due to the convexity of the training cost $c(\cdot)$, the marginal cost, which is associated with the increase in the fraction of unskilled workers, is increasing in $n_{l} / l$. Therefore, those firms which decide to hire more workers will also demand relatively more unskilled employees in order to balance the equality between the marginal benefit and the marginal cost.

The third statement of Lemma 1 connects the preceding analysis with the effect of "between-firm distribution" triggered by the introduction of a wage subsidy for hiring unskilled workers. It says that as the wage of unskilled workers decreases (for example, due to the introduction of targeted employment subsidies), the profit of the large firms rises at a higher rate than the profit of small firms. Correspondingly, if this wage reduction is financed by a proportionate profit tax, ${ }^{10}$ the after-tax profit decreases for

\footnotetext{
${ }^{10}$ It is easy to see that if the subsidy is financed by a payroll tax, or by a tax on the wage income of
} 

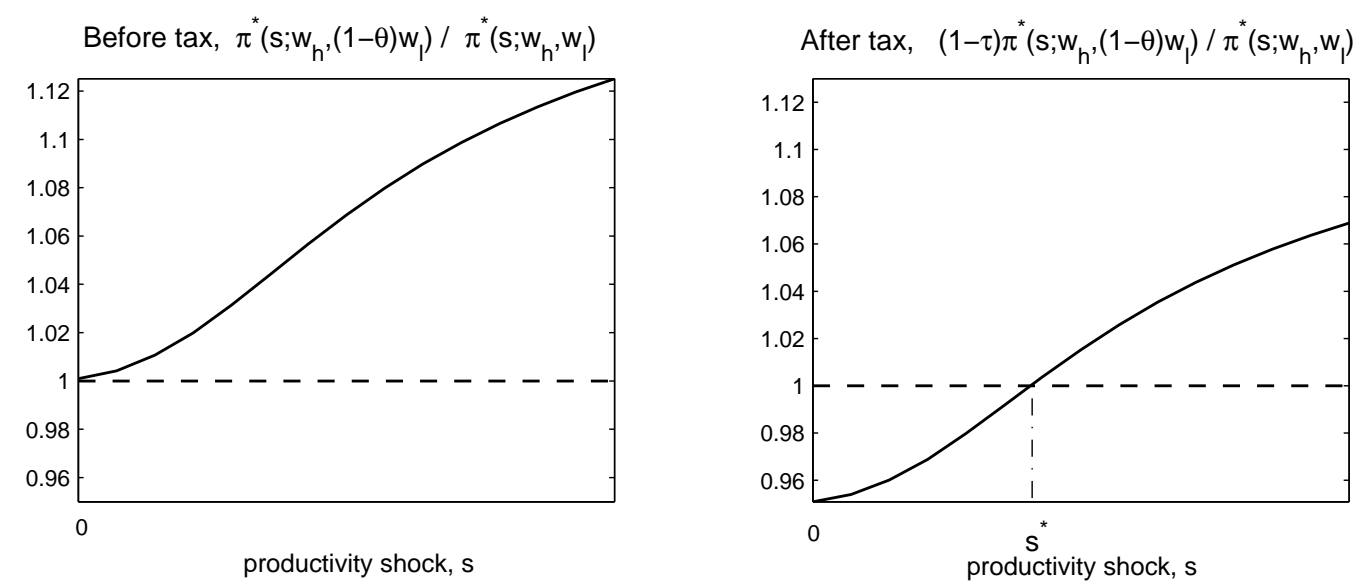

Figure 1: The effect of change in the unskilled workers' wage $w_{l}$ on firms profit as a function of firms' productivity level.

the small firms and rises for the large ones after the subsidy is introduced.

For better exposition, Figure 1 illustrates the relative change in the profit as a function of firms' productivity that occurs if the wage of unskilled workers falls by 10 per cent. The left panel plots the change in before-tax profit, $\pi^{*}\left(s ; w_{h},(1-\theta) w_{l}\right) / \pi^{*}\left(s ; w_{h}, w_{l}\right)$. Note that, according to the last statement of Lemma 1, the wage reduction has very little effect on the profit of a small firm. This happens because small firms hire very few unskilled workers. The right panel of Figure 1 plots the after-tax change in the profit. For every positive tax rate $\tau>0, \lim _{s \rightarrow 0}\left((1-\tau) \pi^{*}\left(s ; w_{h},(1-\theta) w_{l}\right) / \pi^{*}\left(s ; w_{h}, w_{l}\right)\right)<1$, so all firms with relatively low productivity levels $\left(s<s^{*}\right)$ experience a decrease in their instantaneous profit, and those with $s>s^{*}$ benefit from the introduction of the subsidy. Obviously, in this example the tax rate is chosen arbitrarily $(\tau=0.05)$. In a general equilibrium framework, it is determined by a government budget constraint, which is later defined in Section 4.

Finally, condition (3) that appears in the statement of Lemma 1 imposes a lower bound on the curvature of the training cost function. This condition guarantees that the second order conditions for the firms' maximization problem are satisfied, stipulates that the firms' optimal choice is unique and also implies that a firm's size increases as the wage of unskilled workers falls. At the same time, condition (3) holds for a broad range of parameter values. For example, if $\alpha=0.64$ (which corresponds to a labor share of output observed in the US data) and $w_{l} / w_{h}=0.66$ (which is consistent with

skilled employees, the same redistribution effect occurs. In the latter case, it even becomes stronger because an implicit increase in the relative labor cost of skilled employees works in the same direction as a reduction of the wage of unskilled workers, thereby reinforcing the redistribution effect. 
the relative wages of workers with different education), the parameter $\gamma$ should exceed 0.26 in order to satisfy (3). A calibrated value of $\gamma$ that is used in the numerical exercise in Section 4 is higher that this lower bound $(\gamma \approx 0.83)$.

\subsection{The effect of targeted employment subsidies on firms' life- time value}

This section characterizes the stay/exit decision of the firms that have already entered into the industry and argues that the introduction of a subsidy for unskilled employees, financed by a profit tax, decreases the value of small firms and increases the value of large ones. The entry decision and its relation to aggregate dynamics are described in the following section.

Assume that firms decide whether to stay or exit before the realization of their current productivity shock. If the outside opportunity is normalized to zero, the value of the firm that has decided to stay in the industry in the current period is given by

$$
V\left(s ; w_{h}, w_{l}\right)=\pi^{*}\left(s ; w_{h}, w_{l}\right)+\frac{1}{1+r} \int \max \left\{0, V\left(s^{\prime} ; w_{h}, w_{l}\right)\right\} d Q\left(s^{\prime} \mid s\right),
$$

where $r$ denotes a risk-free interest rate. Before characterizing the properties of $V\left(s ; w_{h}, w_{l}\right)$, I make the following assumptions about the properties of the process of firms' productivity shocks:

ASSUMPTION 1 (Continuity and monotonicity) $Q\left(s^{\prime} \mid s\right)$ is continuous in both $s$ and $s^{\prime} ; Q(\cdot \mid s)$ is strictly decreasing in $s$.

Continuity implies that if $V\left(s^{\prime} ; w_{h}, w_{l}\right)$ is a continuous function of $s^{\prime}$ then $\int V\left(s^{\prime} ; w_{h}, w_{l}\right) d Q\left(s^{\prime} \mid s\right)$ is also continuous in $s$. From monotonicity it follows that the integral in the right hand side of equation (4) preserves the monotonicity of $V\left(s^{\prime} ; w_{h}, w_{l}\right)$ with respect to $s^{\prime}$.

ASSUMPTION 2 (Absorbing state) $Q(0 \mid 0)=1$, i.e. $s=0$ is an absorbing state.

In the modeled environment this assumption is necessary to generate positive flows of entry and exit. Due to the absence of a fixed production cost, the current profit of firms is nonnegative at any level of productivity shock. Correspondingly, the value of the firm with zero productivity level would be positive if assumption 2 were not imposed (because even not operational firms would have a positive probability of becoming productive again in the future), and no exit would ever occur. The absence of a fixed 
production cost is obviously a simplifying assumption but it allows for the abstraction from the policy's impact on the average productivity in the industry, thus allowing us to focus on the between-firms distributional effect.

In addition, Assumption 2 guarantees that the after-tax present value of expected life-time profit decreases for the firms with sufficiently low productivity levels after the targeted employment subsidy is introduced. If $s=0$ were not an absorbing state, it could happen that the value of small firms would increase after the introduction of the subsidy, given that the probability of getting high productivity in the future is large enough. On the other hand, if low productivity shocks are sufficiently persistent (as it is reported in the data), the results of Lemma 2 will still be valid even if Assumption 2 does not hold. In other words, neither of the two implications of Assumption 2 is crucial for the validity of the main argument of the paper, but they both allow for the conveying of the idea in a more illustrative way.

Lemma 2 If all assumptions of Lemma 1 hold and the process of firms' productivity shocks satisfies Assumptions 1 and 2, then dynamic programming problem (4) has a unique solution $V\left(s ; w_{h}, w_{l}\right)$, such that:

(i) $V\left(s ; w_{h}, w_{l}\right)$ is increasing and continuous in $s, V\left(s ; w_{h}, w_{l}\right)>0$ if and only if $s>0$;

(ii) $\left|\partial V\left(s ; w_{h}, w_{l}\right) / \partial w_{l}\right|$ is increasing in $s$;

(iii) $\lim _{s \rightarrow 0} \frac{V\left(s ; w_{h},(1-\epsilon) w_{l}\right)}{V\left(s ; w_{h}, w_{l}\right)}=1$ for all $\epsilon \in(0,1)$;

(iv) for every $\epsilon \in(0,1)$ and $\tau>0$, there exist such $\widehat{s}$ that $V_{\tau}\left(s ; w_{h},(1-\epsilon) w_{l}\right)<$ $V\left(s ; w_{h}, w_{l}\right)$ for all $s<\widehat{s}$, where

$$
\begin{aligned}
V_{\tau}\left(s ; w_{h},(1-\epsilon) w_{l}\right)= & (1-\tau) \pi^{*}\left(s ; w_{h},(1-\epsilon) w_{l}\right)+ \\
& +\frac{1}{1+r} \int \max \left\{0, V_{\tau}\left(s^{\prime} ; w_{h},(1-\epsilon) w_{l}\right)\right\} d Q\left(s^{\prime} \mid s\right) .
\end{aligned}
$$

Lemma 2 establishes that the properties of the instantaneous profit $\pi^{*}\left(s ; w_{h}, w_{l}\right)$ are mapped into similar properties of the firms' life-time value $V\left(s ; w_{h}, w_{l}\right)$, and only the firms with sufficiently high productivity levels $(s>\widehat{s})$ may benefit from the presence of the targeted employment subsidies (conditional on the tax rate $\tau$ and wages $w_{h}$ and $w_{l}$ being fixed). 
In order to proceed with the definitions of equilibrium, it is now necessary to describe how the distribution of firms' productivity levels evolves over time and how it relates to the distribution of entrants' productivity shocks and the number of entering firms. This mechanism is characterized in the following section and is similar to the formalization of firm dynamics in Hopenhayn (1993).

\subsection{Aggregate Firm Dynamics}

At the beginning of each period, before the individual productivity shocks are drawn, an unlimited number of potential firms face an option of entering into the industry. If a firm decides to enter, it receives a productivity shock from the distribution characterized by c.d.f. $G(s), s \in[0, \bar{s}]$. Its future productivity shocks follow the Markov process $Q\left(s^{\prime} \mid s\right)$ described above. Opening up a firm requires fixed cost $\eta$, which should be paid before the initial productivity shock is drawn.

If the markets are perfectly competitive, entry into the industry occurs as long as the present value of expected life-time profit for the entrants exceeds entry cost $\eta$. No firms are willing to enter if the following condition holds:

$$
\int V\left(s ; w_{h}, w_{l}\right) d G(s)=\eta
$$

The above free entry condition determines the equilibrium number of firms entering into the industry every period. It is balanced through the mechanism of wage determination on the labor market. For example, if too many firms enter, the aggregate demand for labor input is very large. If the number of potential workers is limited (e.g., the population size is restricted), high labor demand drives wages up and pushes firms' expected value below the entry cost. This makes entry unprofitable and discourages potential start ups. On the contrary, if very few firms enter, the wages are low and firms' profits are high. In this case, the number of entering firms increases until equality is reached in the free entry condition (6).

Equation (6) plays the crucial role in analyzing the effects of labor market policies. In particular, the larger the decrease in the left hand side of the free entry condition generated by the introduction of the employment subsidy, the more firms would have to exit from the industry, and, as a consequence, aggregate employment may fall. This is likely to happen if the distribution of entrants' productivity shocks is concentrated over the relatively small values of $s$, because, as it has been shown in the previous Section, the after-tax value of sufficiently small firms decreases when the subsidy program is 
implemented.

To describe formally the link between the aggregate labor demand and the flow of entrants, one has to characterize the law of motion of the distribution of firms' productivity shocks. Assume that by the end of period $t$ the aggregate distribution of firms' productivity levels is described by the density function $\mu_{t}(S)$ (S is from the Borel set of $[0, \bar{s}])$, and $\lambda_{t+1}$ firms decide to enter into the industry at the beginning of the period $t+1$, then the distribution of firms' productivity shocks $\mu_{t+1}$ by the end of period $t+1$ is given by

$$
\mu_{t+1}\left(\left[0, s^{\prime}\right]\right)=\int_{s \in(0, \bar{s})} Q\left(s^{\prime} \mid s\right) d \mu_{t}(s)+\lambda_{t+1} G\left(s^{\prime}\right) .
$$

The first term in the above expression describes how the distribution of existing firms changes from period $t$ to period $t+1$ and accounts for those firms who receive productivity shock $s=0$ in period $t$ and exit from the industry. The second term adds to it the distribution of newcomers' productivity shocks.

ASSUMPTION 3 For every $s \in[0, \bar{s}]$, there exist $N \geq 1$ such that $Q^{N}(0 \mid s)>0$.

This assumption suggests that every firm exits with positive probability within a finite number of periods. As a consequence of this assumption, it can be shown that every firm's expected life-time is finite. Precisely this condition is driving the existence of stationary distribution of firms' productivity shocks in the long run.

Lemma 3 If $Q\left(s^{\prime} \mid s\right)$ satisfies Assumptions 1-3, $G(0)<1$ and $\lambda_{t}=\lambda$ for all $t \geq 0$, then

(i) there exists a unique distribution $\mu_{\lambda}$ such that $T^{n} \mu_{0} \Rightarrow \mu_{\lambda}$ for every $\mu_{0}$ :

$$
\mu_{\lambda}\left(\left[0, s^{\prime}\right)\right)=\int_{s \in(0, \bar{s})} Q\left(s^{\prime} \mid s\right) d \mu_{\lambda}(s)+\lambda G\left(s^{\prime}\right)
$$

(ii) if $\lambda_{1}=k \lambda$, then $\mu_{\lambda_{1}}=k \mu_{\lambda}$.

(Proof of this Lemma follows the line of argument in Hopenhayn (1993).)

In other words, the presence of an absorbing state guarantees the existence of unique invariant distribution $\mu_{\lambda}$ with a relatively limited number of assumptions. Intuitively, the evolution of $\mu_{t}$ can be decomposed into two processes. On one hand, as time goes on, 
more of those firms that were present in the industry at time 0 exit. After sufficiently many periods very few of them remain active, therefore the limiting distribution $\mu_{\lambda}$ (if it exists) is not affected by the initial distribution $\mu_{0}$. On the other hand, $\lambda$ firms open up every period and at least some of them receive positive productivity shocks (since $G(0)<1$ ). This prevents the industry from dying out. The fact that every firm's expected life time is finite guarantees that the distribution generated by the inflow of new firms every period does not explode and converges to a finite distribution $\mu_{\lambda}$, as it is stated in (i) of Lemma 3.

Therefore, if the number of entrants $\lambda$ and the distribution of their productivity shocks $G(\cdot)$ are known, the aggregate labor demands in the stationary allocation are given by

$$
\begin{aligned}
& N_{h}^{D}\left(w_{h}, w_{l}, \lambda\right)=\int_{0}^{\bar{s}} n_{h}\left(s ; w_{h}, w_{l}\right) d \mu_{\lambda}(s), \\
& N_{l}^{D}\left(w_{h}, w_{l}, \lambda\right)=\int_{0}^{\bar{s}} n_{l}\left(s ; w_{h}, w_{l}\right) d \mu_{\lambda}(s) .
\end{aligned}
$$

Before switching to a formal definition of equilibrium allocations, it is useful to formulate the following result describing the properties of the aggregate labor demand:

Lemma 4 Assume that all the conditions of Lemma 1 hold and $Q\left(s^{\prime} \mid s\right)$ satisfies Assumptions 1-3. Then for every $\lambda>0$

(i) $\frac{\partial N_{l}^{D}\left(w_{h}, w_{l}, \lambda\right)}{\partial w_{l}}<0$ and $\frac{\partial N_{h}^{D}\left(w_{h}, w_{l}, \lambda\right)}{\partial w_{h}}<0$.

(ii) If, in addition, $\gamma>\frac{1-\alpha}{1-w_{l} / w_{h}}-1$, then $\frac{\partial N_{h}^{D}\left(w_{h}, w_{l}, \lambda\right)}{\partial w_{l}}<0$.

The above lemma characterizes how aggregate demands for labor respond to changes in the wage rates. Part (i) of Lemma 4 states an obvious result: if a wage for any type of labor falls, firms respond by hiring more workers of this type. The second result of Lemma 4 is less obvious and is driven by the convexity of the training cost as a function of the fraction of unskilled employees. In particular, part (ii) claims that a decrease in the wage of unskilled workers not only stimulates the demand for unskilled labor but also drives up the demand for skilled employees, thus creating a complementarity between both types of workers.

Intuitively, in response to a decrease in $w_{l}$, the firm would primarily increase the number of its unskilled workers. If, at the same time, the firm does not adjust the number of its skilled employees, the fraction $n_{l} / n_{h}$ increases too fast. Since the training cost is convex, this could imply that the firm's expenditures on training grow faster 
than its benefits resulting from a fall in $w_{l}$. Thus, in order to slow down the growth of the marginal training cost, the firm must also increase the number of its unskilled employees.

Obviously, the above argument will apply only if the degree of convexity of the training cost function is large enough, which is stipulated by additional condition $\gamma>\frac{1-\alpha}{1-w_{l} / w_{h}}-1$ that appears in the second part of Lemma 4. Note that the firm's productivity $s$ does not enter this inequality, implying that the two types of labor are substitutes in all incumbent firms, independent of their size. Clearly, this condition could be relaxed if certain properties are known about the distribution of firms' productivity shocks $\mu_{\lambda}$. In particular, for every individual firm the result of (ii) would hold if its current fraction of unskilled workers $n_{l} /\left(n_{l}+n_{h}\right)$ is small enough (it is easy to verify that the last statement of Lemma 4 is always true if $\left.n_{l} /\left(n_{l}+n_{h}\right) \rightarrow 0\right)$. However, even in its general form, condition $\gamma>\frac{1-\alpha}{1-w_{l} / w_{h}}-1$ is not too restrictive. For the parameter values used in the numerical exercise in Section 4, this condition is weaker than condition (3) required in Lemma 1.

Recalling that the assumption of convexity of training cost can be derived from the assumption of on-the-job training provided by the skilled employees to their less skilled colleagues, the second result of Lemma 4 becomes very intuitive: if a firm increases the number of employees requiring additional training, it must also hire more workers who are able to provide this training, otherwise it incurs very large losses.

Such complementarity property is obviously an extreme case and is unlikely to find strong support in the data. However, it turns out to be very helpful in conveying the main argument of this paper: I show that even in the presence of such complementarity, the redistributional effect can revert the predictions of policy analysis. Lemma 4 implies that a reduction in the wage for unskilled workers would stimulate demand for both types of employees, thus suggesting that the introduction of an employment subsidy could potentially have a positive impact on total employment if the number of entrants $\lambda$ remains unchanged. However, this prediction may fail if $\lambda$ is determined endogenously because an increase in labor demand for skilled workers can be outweighed by an endogenous decrease in the number of operating firms arising due to profit redistribution from young to mature firms. This mechanism is studied more carefully in the following section. 


\section{Equilibrium Allocation and Policy Analysis}

This section defines an equilibrium allocation and explains why accounting for general equilibrium effects arising due to endogeneity of the number of firms in the economy might have important implications for evaluating employment subsidy programs. The analysis in the first part of this section does not specify how labor supply is generated because the results formulated below hold for any increasing labor supply function. However, a particular shape of labor supply has to be chosen if one wants to relate the results to the data and analyze numerically the effects of targeted employment subsidies. That is why the last part of this section presents one possible example of endogenizing labor supply curves which explains how unemployment arises.

\subsection{Stationary equilibrium allocation}

Assume that the labor supply curves of both types of labor are given by the upward sloping functions $N_{h}^{S}\left(w_{h}\right)$ and $N_{l}^{S}\left(w_{l}\right) \cdot{ }^{11}$

Definition 1 Given production technology $s f(\cdot)$, training cost function $c(\cdot)$, law of motion of firms' productivity shocks $Q(s, S)$, distribution of shocks for entrants $G(s)$, entry cost $\eta$, and workers' labor supply curves $N_{h}^{S}\left(w_{h}\right)$ and $N_{l}^{S}\left(w_{l}\right)$, a stationary recursive competitive equilibrium with fixed entry is defined by the value function $V\left(s ; w_{h}, w_{l}\right)$, hiring policies $n_{h}\left(s ; w_{h}, w_{l}\right)$ and $n_{l}\left(s ; w_{h}, w_{l}\right)$, wages $\left(w_{h}, w_{l}\right)$, the number of entrants $\lambda$ and the distribution $\mu_{\lambda}$ of firms' productivity shocks such that:

(i) $V\left(s ; w_{h}, w_{l}\right)$ and $n_{i}\left(s ; w_{h}, w_{l}\right), i=h, l$ solve the firms' profit maximization problem $(4)$;

(ii) wages $w_{h}$ and $w_{l}$ are such that labor markets for both types of employees clear:

$$
\begin{aligned}
& N_{h}^{D}\left(w_{h}, w_{l}, \lambda\right)=N_{h}^{S}\left(w_{h}\right), \\
& N_{l}^{D}\left(w_{h}, w_{l}, \lambda\right)=N_{l}^{S}\left(w_{l}\right),
\end{aligned}
$$

where the aggregate labor demand functions $N_{h}\left(w_{h}, w_{l}, \lambda\right)$ and $N_{l}\left(w_{h}, w_{l}, \lambda\right)$ are defined in (8) and (9);

\footnotetext{
${ }^{11}$ Note that in this simple specification, labor supply of one type of workers is independent of the wage paid to another type of employees, suggesting that workers' types cannot change throughout their lives. A more realistic framework should allow for transition between different groups; in this case the distributional effect could still be important, though the mechanism could be less transparent.
} 
(iii) $\mu_{\lambda}$ is a stationary distribution of firms' productivity levels generated by a constant flow of entrants $\lambda$ as it is defined in ( 7$)$;

(iv) entry into the industry is competitive, i.e., the free entry condition (6) holds:

$$
\int V\left(s ; w_{h}, w_{l}\right) d G(s)=\eta
$$

In the remainder of the paper this equilibrium allocation is referred to as a free entry equilibrium because it stipulates that the free entry condition is satisfied with equality. Altogether, conditions (10) and (6) constitute a system of three equations with three unknown aggregate variables - wages $w_{h}$ and $w_{l}$, and the number of entrants $\lambda$.

As an alternative to a free entry equilibrium, one could also consider an economy where the total number of firms is fixed endogenously, i.e., $\hat{\lambda}$ is a parameter rather than exogenous variable. In such an economy the free entry condition (6) would not necessarily hold, while the conditions (i)-(iii) would still have to be satisfied in an equilibrium allocation. For convenience, let us label such equilibrium allocation, characterized by an exogenous parameter $\lambda$, as a fixed entry equilibrium with $\widehat{\lambda}$ entrants. $^{12}$

\subsection{The effects of targeted employment subsidies}

Consider the following policy experiment. Assume that the government subsidizes firms for hiring unskilled workers by compensating a fraction $\theta$ of these workers' wage $w_{l}$. Suppose that the government finances these subsidy expenditures by levying a profit tax at a flat rate $\tau$. This means that firms' cost of hiring an unskilled worker drops to $(1-\theta) w_{l}$, and, correspondingly, firms' value $V_{\tau}\left(s ; w_{h},(1-\theta) w_{l}\right)$ is now given by the maximization problem (5). Note also that profit tax financing does not affect firms' hiring policies because their labor decision is derived from the instantaneous profit maximization problem. ${ }^{13}$

\footnotetext{
${ }^{12}$ In a general case, it is not possible to claim either existence or uniqueness of any of the defined above equilibria. Multiple equilibria can occur due to the fact that the condition

$$
\frac{N_{h}^{D}\left(w_{h}, w_{l}, \lambda\right)}{N_{l}^{D}\left(w_{h}, w_{l}, \lambda\right)}=\frac{N_{h}\left(w_{h}\right)}{N_{l}\left(w_{l}\right)}
$$

which should always hold in the equilibrium due to (10), may generate a non-monotone relationship between $w_{l}$ and $w_{h}$ for any given $\lambda$. That is why in the numerical example in the last section of the paper I choose such a set of parameters that the benchmark free entry equilibrium is unique, and then I study the deviations around this equilibrium generated by the introduction of the subsidy program.

${ }^{13}$ This implication is not crucial for the analysis in this paper. Any other form of financing, e.g., payroll or output taxation, would lead to a redistribution effect as long as it is "spread" across all
} 
In an equilibrium allocation, the government should determine tax and subsidy rates in such a way that the government budget constraint holds with equality:

$$
\tau \int \pi^{*}\left(s ; w_{h},(1-\theta) w_{l}\right) d \mu_{\lambda}(s)=\theta w_{l} N_{l}^{D}\left(w_{h},(1-\theta) w_{l}, \lambda\right)
$$

where $\pi^{*}\left(s ; w_{h},(1-\theta) w_{l}\right)$ is the optimal value of firms' instantaneous profits found in (2) and $N_{l}^{D}\left(w_{h},(1-\theta) w_{l}, \lambda\right)$ is the function of firms' aggregate demand for unskilled labor defined earlier in (9).

Such a government policy has the potential to reduce unemployment since, according to (ii) of Lemma 4, it drives up individual firms' demand for both types of labor. That is why, after the subsidy program is implemented, the economy's employment should increase if the total number of operating firms remains unchanged, as happens in a fixed entry equilibrium. In contrast, in a free entry equilibrium, an endogenous change in the number of firms may outweigh an increase in individual firms' demand. This could happen if the new subsidy program crowds out some firms from the industry by, for example, inducing substantial redistribution of profit from young to mature firms. The following Proposition formally states this intuitive result.

PROPOSITION 1 Assume that $f(l)=l^{\alpha}, c(\cdot)$ is given by (1) and $Q\left(s^{\prime} \mid s\right)$ satisfies Assumptions 1-3. Suppose also that labor supply curves $N_{h}^{S}\left(w_{h}\right)$ and $N_{l}^{S}\left(w_{l}\right)$ are upward sloping. Then:

(A) in an economy with the fixed number of entering firms $\hat{\lambda}$, equilibrium wages, total employment as well as employment rates of each group of workers rise after the introduction of the subsidy program;

(B) in a free entry equilibrium, in which the number of entering firms $\lambda$ is determined endogenously, the introduction of the subsidy program

(i) has an ambiguous effect on the number of entering firms $\lambda$ as well as on unemployment rates and wages of each particular group of workers;

(iii) discourages entry if $G\left(s^{*}\right)=1$ for some $s^{*}<\bar{s}$, i.e., if entrants are sufficiently small compared to mature firms; in this case unemployment among skilled workers rises.

In order to understand better the results of the above proposition, it is convenient to analyze in the first place how the introduction of the employment subsidy affects the firms. Adopting the assumption of profit taxation makes the analysis more transparent. 
value of the entrants in a fixed entry economy. Since the subsidy stimulates firms' demand for both types of workers, both wages would increase in a fixed entry equilibrium. Depending on the elasticities of labor demand and supply functions, these increases can be large or moderate. In any case, the value of the large firms, who benefit from hiring larger fractions of subsidized unskilled workers, goes up. However, if the accompanying rise in the skilled workers' wage (driven by the large firms' necessity to hire more skilled workers in order to reduce marginal training cost) is substantial, the value of the small firms, who hire almost no unskilled labor, is likely to decrease. Therefore, even if only due to complementarity of employees with different skills, the introduction of the subsidy program may induce a redistribution of profits from small to large firms.

On top of it, a new profit tax, imposed to finance the subsidy payments, makes this redistribution effect more pronounced. As it has been suggested by Lemmas 1 and 2, the large firms' one-period gross profit increases at a higher rate than the profit of small firms, thus implying that the after-tax profit of the smallest firms falls, while the large firms' after-tax profit might still be higher than in the benchmark economy. Correspondingly, if the entrants are sufficiently small, the introduction of the targeted employment subsidies would necessarily reduce the entrants' value, thus triggering the exit of firms from the industry. As firms exit, the aggregate demand levels for both types of workers decrease, thereby causing the drop in wages $w_{l}$ and $w_{h}$ below their levels in a subsidized fixed entry equilibrium. This generates a decrease in corresponding employment levels, thereby making the total effect of the subsidy ambiguous. Obviously, a simple intuitive argument also suggests that if the subsidy level is quite high, a large fraction of firms would experience a decrease in the after-tax profit in the fixed entry equilibrium. This would discourage many firms from entering the industry, and, correspondingly, total employment would be likely to drop after the introduction of a subsidy.

Finally, it is also important to notice that the fall in the number of entering firms should not necessarily be driven by a profit redistribution from young to mature firms, but may also arise due to a distortionary effect of the employment subsidies. ${ }^{14}$

\footnotetext{
${ }^{14}$ This argument is best illustrated by analyzing the response to the subsidy program in an industry with homogeneous firms. In the absence of frictions, the economy's welfare, measured as a sum of firms' and workers' total surplus, decreases after the introduction of distortionary employment subsidies. In a fixed entry equilibrium, due to an increase in wages and employment levels of both types of employees, the workers' total surplus rises. Correspondingly, firms' surplus decreases after the new government policy is implemented. Since the entrants' value coincides with the average incumbent's value in the homogenous industry, some firms would necessarily exit after the subsidy is introduced. This is not necessarily true if the firms are heterogeneous because in that case the value of the average operating
} 


\subsection{Workers' labor supply: an example}

The following section presents one possible way of endogenizing the relationship between workers' wages and unemployment rates. It uses a simple version of the ShapiroStiglitz shirking model to derive the functions $N_{h}^{S}\left(w_{h}\right)$ and $N_{l}^{S}\left(w_{l}\right)$ and shows that both functions are strictly increasing, as it is required in Proposition 1.

Suppose that at any period of time a worker can be employed by at most one firm. Within a period, the employer does not observe worker's effort level. However, in the end of the period the employer is able to monitor the amount of effective labor supplied by his employee. It is commonly known that workers' effective labor supply is correlated with the worker's effort level: if the employee exerts full effort his effective labor supply is equal to 1 with probability $q>0$, but if the worker shirks he supplies zero units of effective labor.

Each period the worker and the employer sign a contract, which specifies the wage $w_{i}(i=h, l)$ that the worker receives independent of his realized productivity and a punishment for supplying zero units of effective labor. If this happens, the worker loses his/her job, earns a bad reputation and remains unemployed in the following period. In future periods he would be reemployed with probability $\lambda_{i}$, in which case he would be treated similarly to the employees with a good employment history. Therefore, as in the Shapiro-Stiglitz model, in this framework unemployment serves as a disciplining device that is necessary to prevent workers from shirking. ${ }^{15}$

Workers are risk-neutral and their disutility from exerting a full effort level is equal to $b$. Naturally, due to risk neutrality, workers discount future income at the same rate $\beta$ as firms do. Denote by $V_{E}^{i}, V_{S}^{i}$ and $V_{B}^{i}$ values of (i) being employed and exerting full effort; (ii) being employed and shirking; (iii) being unemployed due to having a bad reputation, $i=h, l$. Formally, these values are related to each other in the following

firm exceeds the value of the entrants due to an obvious selection effect.

${ }^{15}$ In contrast to the Shapiro-Stiglitz model, I add a reputational aspect into the employment contract because it is important to distinguish between firing due to bad performance and separation due to a decrease in the firm's optimal size (caused by a decline in the firm's productivity). If no such distinction were made, contracts would vary across firms with different productivity shocks, thus generating acrossfirms wage differentials. Though potentially interesting, such framework would complicate the analysis in this paper and shift the focus away from the paper's main subject. 
way:

$$
\begin{aligned}
V_{E}^{i} & =w_{i}-b+\beta\left[q V_{E}^{i}+(1-q) V_{B}^{i}\right], \\
V_{S}^{i} & =w_{i}+\beta V_{B}^{i}, \\
V_{B}^{i} & =\beta\left[\lambda_{i} V_{E}^{i}+\left(1-\lambda_{i}\right) V_{B}^{i}\right] .
\end{aligned}
$$

If the employment contract is designed properly, workers never decide to shirk, i.e., the incentive constraint $V_{E}^{i} \geq V_{S}^{i}$ must be satisfied implying that

$$
\beta q\left(V_{E}^{i}-V_{B}^{i}\right) \geq b
$$

Obviously, in a competitive labor market the incentive constraint should be satisfied with equality. Combining (13) with the first and the last equations from (12) results in

$$
w_{i}=\frac{b}{\beta q}\left(1+\beta \lambda_{i}\right)
$$

In the steady state, $\lambda_{i}$ determines the unemployment rate $u_{i}$ among $i$-type workers. Recalling that only workers with a bad reputation experience difficulties finding a new job after being fired, it is obvious that

$$
1-u_{i}=(1-q)\left(1-u_{i}\right)+\lambda_{i} u_{i}
$$

Together with (14), the above equation implies that

$$
u_{i}=\frac{\beta(1-q)}{\beta q w_{i} / b-1+\beta(1-q)} .
$$

Correspondingly, the total employment level of the workers of type $i$ is equal to

$$
N_{i}^{S}\left(w_{i}\right)=\overline{N_{i}}\left(1-u_{i}\right)=\overline{N_{i}}\left(1-\frac{\beta(1-q)}{\beta q w_{i} / b-1+\beta(1-q)}\right), \quad i=l, h,
$$

where $\overline{N_{i}}$ is the total number of workers of type $i$ living in the economy. Note that $N_{i}^{S}\left(w_{i}\right)$ is a strictly increasing function, as was required in Proposition 1. In addition, (17) implies that the unemployment rate among unskilled workers is higher than the unemployment rate among skilled workers because condition $w_{h}>w_{l}$ is necessary to generate positive demand for unskilled labor.

Finally, it is also necessary to account for the fact that a fraction $1-q$ of firms' 
employees fail to supply any effective labor. This is easily corrected by modifying firms' production function in the following way:

$$
\widetilde{f}(l)=f(q l) .
$$

Since such transformation preserves all the stipulated above properties of the production function, all the preceding results remain valid for $\widetilde{f}(l)$.

\section{Numerical Analysis}

This section presents the results of a simulation exercise illustrating that while evaluating the expected policy's outcomes it is important to take into consideration the structure of the production sector. First, it might be crucial to account for a potential change in the number of operating firms if the entry into the industry is competitive. Second, heterogeneity between young and mature firms is also likely to play an important role in policy analysis because it can aggravate the policy's adverse effect on the number of existing firms. The numerical example below shows that overlooking any of these two aspects may generate wrong predictions about the expected effects of the subsidy program.

\subsection{Calibration procedure}

The first part of this section describes the calibration procedure. The parameter values are chosen in such a way that the properties of the free-entry equilibrium allocation are consistent with the data on firms' growth and survival, amount of employer-provided training as well as the distribution of workers' wages and unemployment rates. Table 1 lists all the exogenous parameters of the model together with the data sources that are used to pin down the parameters' values.

A time period is equal to one year, thus the time preference rate is set to $\beta=$ $1 /(1+r)=0.9524$, where $r=0.05$ stands for the annual interest rate. In order to set the parameters of the labor supply functions, I use the relationship (16) between the workers' wage and unemployment rates, $w_{i}$ and $u_{i}$, so that their equilibrium values match the distribution of wages and unemployment levels across workers with different skills.

Nickell and Bell (1996) classify US workers into two groups, those with high and low education, and report that: (i) the wages of more educated workers are 1.51 times 
The parameters of the model

\section{Parameter}

Time preference rate, $\beta$

Probability of supplying

full labor, $q$

Curvature of $f(l), \alpha$

Multipl. of the training cost function, $A$

Curv. of the training cost function, $\gamma$

Per employee hrs of training, $\xi$

Vector of prod. shocks, $s$

Transition matrix, $Q$

Distr. of entrants' shocks, $G$

Entry cost, $\eta$

\section{Value Data to match}

0.9524 annual interest rate

0.9734 distribution of wages and unemployment rates

0.64 labor share of output

0.1352 per employee training

0.8249 per employee training

$30.5 \quad$ ratio of empl. levels

see Table 3 grid of firm sizes

see Table 3 firms' growth and exit

see Table 3 size distr. of firms

101.6 average firm size

Table 1: The parameters of the model 
higher than the wages of workers with relatively low education; (ii) unemployment rates among workers with high and low education are equal to $3 \%$ and $11 \%$ respectively; (iii) the average unemployment rate is equal to $6 \%,{ }^{16}$. Normalizing $b=1$ and using (16) it is easy to derive that $q=0.9734$ would generate the equilibrium unemployment rates consistent with the above observations. For this value of $q$, the equilibrium wages should be equal to $w_{h}=1.96$ and $w_{l}=1.3 .{ }^{17}$

To set the parameters of the training cost function I use the data on per employee hours of employer provided training collected by the survey Sept95 of the Bureau of Labor Statistics for the Employer Training Administration of the U.S. Department of Labor. The fifth row of Table 2 reports the amount $h(\bar{l})$ of per employee training (in hours) for firms of various sizes. Note that, consistently with the results presented in Section 2, large firms provide more per worker training than small firms.

In terms of the model's setup, the number of training hours per employee is proportionate to the fraction of unskilled workers $n_{l} /\left(n_{l}+n_{h}\right)$ hired by the firm. The coefficient of proportionality (denote it by $\xi$ ), indicating how many hours of training an unskilled worker must receive, would then be determined by aggregating the total number of unskilled workers across all firms and matching it with the relative amount of unskilled population that is employed in the equilibrium.

For every given $\xi$, the parameters $A$ and $\gamma$ of the training cost function can be chosen to minimize the difference between $h(\bar{l})$ reported in the fifth row of Table 2 and the optimal number of training hours $\xi n_{l}(\bar{l}, A, \gamma) / \bar{l}$ derived endogenously from the firms' profit maximization problem: ${ }^{18}$

$$
\left(A^{*}, \gamma^{*}\right)=\arg \min _{(A, \gamma)}\left\|h(\bar{l})-\xi \frac{n_{l}(\bar{l} ; A, \gamma)}{\bar{l}}\right\| .
$$

The expression in the right hand side of the above equality is computed on the grid of firms' sizes $\bar{l}$, and $h(\bar{l})$ taken from Table 2 .

In turn, $\xi$ is chosen to match the fraction of high skilled workers employed in the

\footnotetext{
${ }^{16}$ Correspondingly, $37.5 \%$ of the total population have low education and the ratio of employed skilled to unskilled workers is equal to 1.82

${ }^{17}$ These levels of $q, w_{h}$ and $w_{l}$ are the unique solution to a system of equations given by (16) written for $i=h$ and $i=l$ together with the condition $w_{h}=1.51 w_{l}$.

${ }^{18}$ The optimal number of unskilled employees $n_{l}(\bar{l} ; A, \gamma)$ is a solution to the first order condition to (2) with respect to $n_{l}$.
} 


\section{Firms in US manufacturing}

\begin{tabular}{lccccc}
\hline \hline & & & & & \\
Number of employees ${ }^{1}, l$ & $0-49$ & $50-99$ & $100-249$ & $250-499$ & $\geq 500$ \\
& & & & & \\
Data: & & & & & \\
Fraction of firms $^{2}, \mu$ & 0.70 & 0.13 & 0.10 & 0.04 & 0.03 \\
Growth rates of survivors $^{3}$ & 0.391 & 0.130 & 0.077 & 0.026 & - \\
Firm exit rates $^{4}$ & 0.379 & 0.346 & 0.291 & 0.191 & - \\
Hours of training $^{4}, h(\bar{l})$ & 3.34 & 8.2 & 11.39 & 14.56 & 16.6 \\
& & & & & \\
Model: & & & & & - \\
Fraction of firms & 0.391 & 0.130 & 0.077 & 0.026 & - \\
Growth rates of survivors & 0.391 & 0.130 & 0.077 & 0.026 & - \\
Firm exit rates & 0.379 & 0.346 & 0.291 & 0.191 & - \\
Hours of training, $\xi n_{l}(\bar{l}) / \bar{l}$ & 3.15 & 7.49 & 11.33 & 14.72 & 16.66 \\
& & & & & \\
\hline \hline
\end{tabular}

Notes:

${ }^{1}$ In the numerical exercise it is assumed that firms' productivity shocks can take six possible values, so that the corresponding employment levels fall in the middle of these size intervals, $\bar{l}=[25,75,175,375,600]$.

${ }^{2}$ Source: Veracierto (2000), Table 2.

${ }^{3}$ Source: This and the next row are taken from Dunne, Roberts and Samuelson (1989). ${ }^{4}$ Source: Frazis, Gittleman, Horrigan and Joyce (1998), Table 3, Column 4. Originally the data are reported for firms with more than 50 employees, so the first number in this row is obtained by extrapolation on the smaller levels of firms' size under the assumption that firms with zero employees provide no training.

Table 2: Firms in US manufacturing 
equilibrium with the one observed in the data. Given the wage levels $w_{h}$ and $w_{l}$,

$$
\frac{N_{h}^{D}\left(w_{h}, w_{l}, \lambda\right)}{N_{l}^{D}\left(w_{h}, w_{l}, \lambda\right)}=\frac{\sum_{i} \mu_{i} n_{h}^{i}}{\sum_{i} \mu_{i} n_{l}^{i}}=\frac{\overline{N_{h}}\left(1-u_{h}\right)}{\overline{N_{l}}\left(1-u_{l}\right)}=1.82,
$$

where $\left\{\mu_{i}\right\}$ stands for the observed in the data size distribution of firms (reported in the third row of Table 2), and the last number is taken from the estimations of Nickell and Bell. (1996) ${ }^{19}$ It is easy to verify that the second term in the above equality is increasing in $\xi$ if $\xi n_{l}(\bar{l}, A, \gamma) / \bar{l}$ approximates $h(\bar{l})$ well enough. Thus $\xi$ is well determined by the condition (19).

Therefore, using (18) and (19), I find that $\gamma=0.8249, A=0.1352$ and $\xi=30.5$ produce the best (in terms of (18)) approximation of the training function if the equilibrium wages are equal to $w_{h}=1.96$ and $w_{l}=1.3 .{ }^{20}$ The corresponding optimal training hours derived from the model are reported in the last row of Table 2.

Further, the vector of firms' productivity shocks $\bar{s}$ is fixed in such a way that the grid vector of firms' possible sizes $\bar{l}$ is derived endogenously from firms' maximization problem (i.e., it solves the first order condition to (2) with respect to $l$ ). Then the empirical evidence on firms' growth and exit rates (summarized in the third and forth rows of Table 2) is used to set the values of the transition matrix $Q$. In turn, the distribution of entrants' productivity shocks is determined as a solution to (7), where the equilibrium size distribution $\left\{\mu_{i}\right\}$ of firms is taken from the data. ${ }^{21}$ The corresponding values of the productivity shocks, the transition matrix $Q$ and the distribution of entrants $G$ are reported in Table 3. Chosen in this way $G$ implies that all the entrants, who account for $35 \%$ of all incumbent firms, are responsible for $19 \%$ of total industry's output (Dunne, Roberts and Samuelson (1988) report this number being equal to $15.2 \%$ in US manufacturing). This means that, on average, entrants are significantly smaller than older firms: in the model the average entrants' number of employees constitutes only $32 \%$ of the average employment of incumbent firms.

At the last stage, the entry cost $\eta$ is set to satisfy the free entry condition given that

\footnotetext{
${ }^{19}$ See footnote 15 .

${ }^{20}$ These computations are made for the production function $f(l)=l^{\alpha}$, in which $\alpha=0.64$ corresponds to the labor share of output. It is easy to see from the first order conditions to the firm's problem that the total firm's expenditures on workers' wages are equal to $w_{h} l-\left(w_{h}-w_{l}\right) n_{l}=s f^{\prime}(l) l=\alpha f(l)$. Note that for this pair $(\alpha, \gamma)$ the second statement of Lemma 4 holds as long as $w_{l} / w_{h} \leq 0.80$ (while in the benchmark equilibrium allocation $\left.w_{l} / w_{h}=0.66\right)$.

${ }^{21}$ As it has been noted before, $\mu_{\lambda}$ is homogenous of degree 1 in $\lambda$, thus implying that the entrants' distribution $G$, if found as solution to (7), is invariant in $\lambda$. Therefore $\lambda=1$ can be used to set $G$ in this calibration exercise.
} 


\section{Firms' productivity shocks}

Vector of productivity shocks, $s$ $\left[\begin{array}{llllll}0 & 9.3949 & 13.2989 & 17.2139 & 21.6806 & 25.0223\end{array}\right]$

Distribution of shocks for entrants, $G$

$$
\left[\begin{array}{llllll}
0.3494 & 0.6086 & 0.0009 & 0.0368 & 0.0028 & 0.0015
\end{array}\right]
$$

Transition matrix, $Q \quad\left[\begin{array}{cccccc}1.0000 & 0 & 0 & 0 & 0 & 0 \\ 0.3796 & 0.5362 & 0.0655 & 0.0186 & 0 & 0 \\ 0.3460 & 0.0046 & 0.6213 & 0.0092 & 0.0190 & 0 \\ 0.2910 & 0 & 0.0081 & 0.6594 & 0.0324 & 0.0091 \\ 0.1910 & 0 & 0 & 0.0029 & 0.7685 & 0.0376 \\ 0.0500 & 0 & 0 & 0 & 0.0665 & 0.8835\end{array}\right]$

Table 3: Values of firms' productivity shocks, distribution of shocks for entrants and transition matrix for incumbents.

the equilibrium wages coincide with the obtained earlier values $w_{h}=1.96$ and $w_{l}=1.3$. In the economy with the parameter levels defined above, the entry cost $\eta$ is equal to 100.6, which constitutes $29 \%$ of the value of the average incumbent firm.

Finally, it has been verified that for the parameter values listed in Table 1 the economy has unique free entry equilibrium, i.e., the system of equations (10) and (6) has a unique solution bundle $\left(w_{h}, w_{l}, \lambda\right)$. To summarize, in this equilibrium allocation, the average economy's unemployment rate is equal to $6 \%$, with unemployment rates among skilled and unskilled workers being equal to $3 \%$ and $11 \%$ respectively. The skilled workers' wage is 1.51 times higher than the wage of their unskilled colleagues. The average incumbent firm hires 76 workers, while the average entering firm employs 24 workers (32\% of the incumbent firm's size). The equilibrium distribution of firms and their growth and survival rates coincide precisely with the data reported in the upper part of Table 2. The hours of employer-provided training derived in the model for different firm sizes are also listed in Table 2. As can be noticed, they approximate very well their empirical counterpart. When measured in terms of firms' output, the smallest and the largest firms spend respectively $1.1 \%$ and $3.6 \%$ of their total revenue on their own employees' training. 

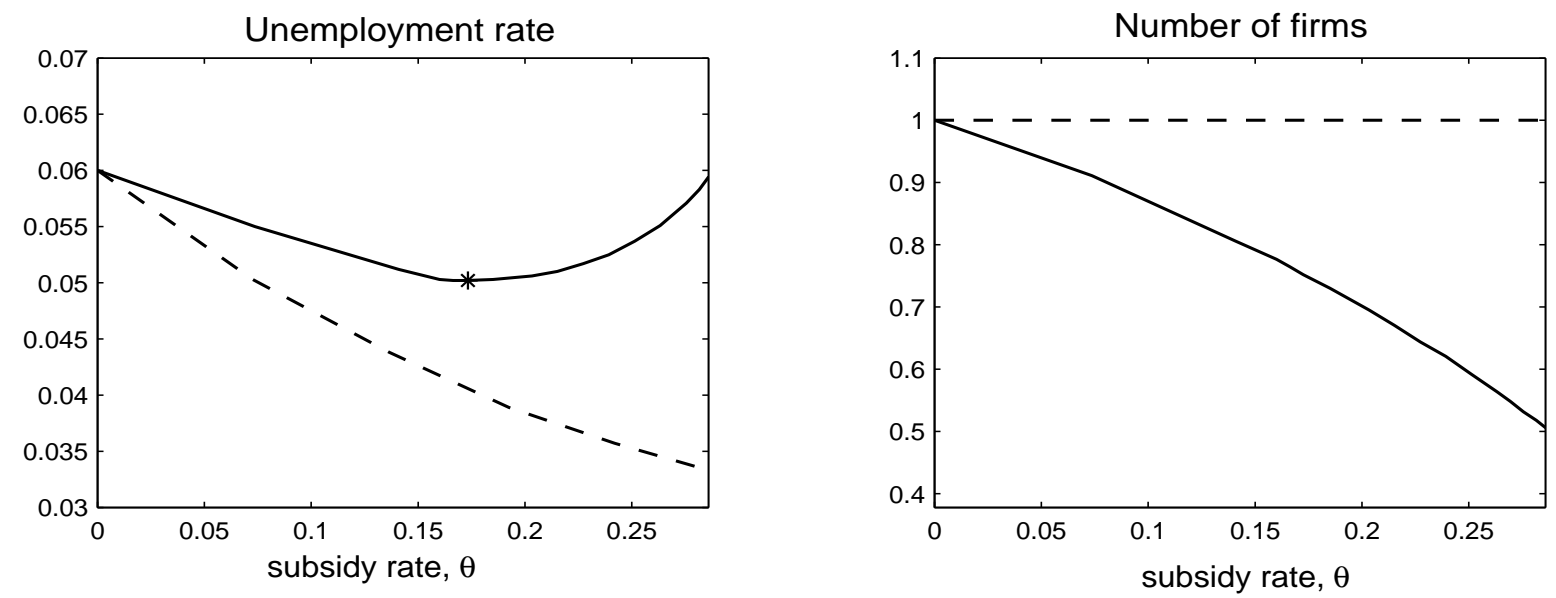

Figure 2: Comparison of the effects of targeted employment subsidies on average unemployment and the number of operating firms in the free entry $(-)$ and fixed entry $(--)$ economies.

\subsection{Policy analysis: the role of competitive entry}

This section compares the effects of targeted employment subsidies on equilibrium allocations in fixed entry and free entry economies. Suppose that in the absence of subsidies the two equilibria are identical and all their endogenous variables coincide with those of the benchmark economy calibrated in the previous section. Now assume that the government subsidizes a fraction $\theta$ of unskilled workers' wage. Figure 2 illustrates the most important differences in the two economies' responses to such a subsidy program. It plots the stationary equilibrium levels of the average unemployment rates and the number of operating firms for different levels of subsidies. The results for the free entry equilibrium are plotted with a solid line.

In a fixed entry equilibrium, the number of firms is fixed exogenously at a given level (normalized to 1), thus the dashed line on the right panel of Figure 2 is completely flat. In contrast, the number of firms in a free entry equilibrium adjusts as the subsidy rate varies: the bigger the subsidy rate, the fewer the firms operating in the industry because the increased tax pressure reduces the value of entrants and discourages start ups.

More striking is the difference in the behavior of average unemployment rates in the two economies illustrated in the upper left panel of Figure 2. In a fixed entry equilibrium, the fraction of the economy's employed population increases as the subsidy rate rises. However, once we account for a general equilibrium effect arising due to endogeneity of the number of firms, the relationship between the subsidy rate and the unemployment level becomes non-monotone. A relatively small subsidy rate stimulates 
labor demand and has a positive effect on the economy's employment. However, as the subsidy becomes sufficiently large (more than 30\%), it has an adverse effect on the value of entrants, is accompanied by a massive exit of firms, and as a result it drives up the average unemployment rate above its value in the benchmark economy. Correspondingly, there exists a level of subsidy which minimizes the aggregate unemployment rate. In this economy it is equal to $17 \%$ and it reduces average unemployment from $6 \%$ to $5 \%$.

Figure 3 provides a more detailed characterization of the economy's response to the targeted employment subsidy program. It explains the described above differences in the behavior of unemployment rates by illustrating how the new policy affects wage and unemployment rates of each group of workers. First, in accordance with (ii) of Lemma 4 , wages and employment levels of both types of workers rise after the introduction of the subsidies because the number of firms in the economy remains unaffected and, at each individual firm's level, skilled and unskilled workers serve as complementary labor inputs.

At the same time, in a fixed entry equilibrium the increased tax pressure pushes the after-tax value of entrants below the level of the entry cost $\eta$. That is why in a free entry equilibrium both wage levels should decrease compared to their values in the fixed entry allocation in order to balance the free entry condition. More formally, such wage reduction is driven by the decrease in the aggregate labor demand stipulated by the exit of firms. After equality in the free entry condition is established, the wage of skilled workers falls below its benchmark level (correspondingly, the unemployment rate of skilled workers rises), but the wage of unskilled workers still remains above its level in a non subsidized economy. Therefore, even though the two labor types are complementary from the viewpoint of every individual firm, they become substitutes at the aggregate level: the targeted employment subsidy program stimulates labor demand for unskilled workers, but the total demand for skilled employees decreases due to a fall in the number of operating firms. ${ }^{22}$

\footnotetext{
${ }^{22}$ Note that the free entry condition dictates a necessary change in wages. Obviously, the size of the associated decrease in the employment rates must depend on the wage elasticity of labor supply $\varepsilon$. In the benchmark economy, the wage elasticity is quite small; it is equal to 0.066 . In order to study the effects of wage elasticity on the equilibrium allocation in a subsidized economy, it would be necessary to depart from the Shapiro-Stiglitz story described in Section 3.4 and to assume that labor supply is given by, for example, a CES function $N_{i}^{S}\left(w_{i}\right)=A_{i} w_{i}^{\varepsilon \overline{N_{i}}}$. From such numerical exercise I find that, other things equal, higher wage elasticity is associated with higher unemployment rates at all subsidy levels. In particular, as $\varepsilon$ changes from 0.05 to 1.5 (empirical estimates usually come up with a number within this interval; see, for instance, Chetty (2003) for a review of empirical studies), the subsidy rate that maximizes total employment in the economy varies from 0.14 to 0.08 .
} 

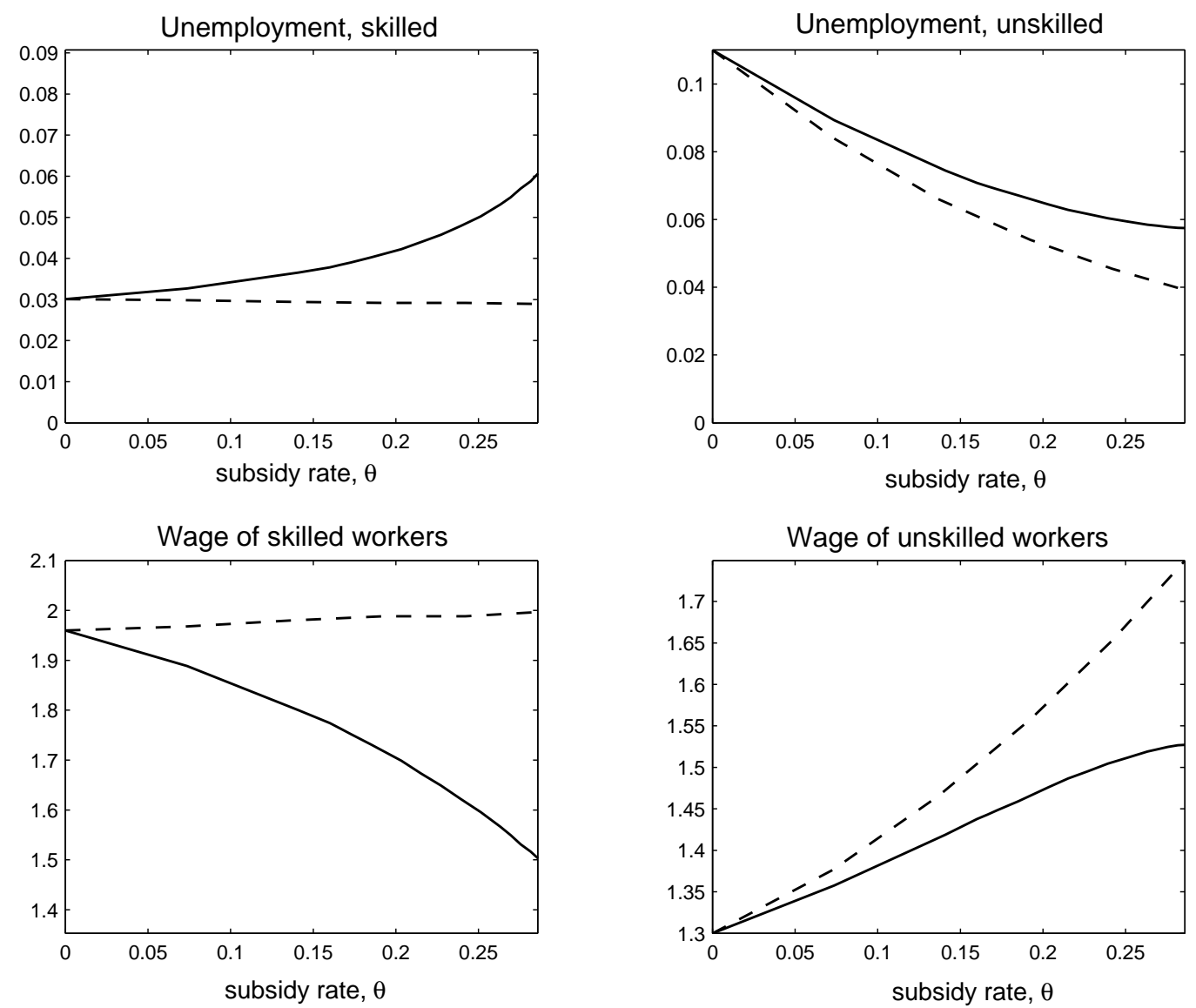

Figure 3: Comparison of the effects of targeted employment subsidies on unemployment rates and wages in the free entry $(-)$ and fixed entry $(--)$ economies. 


\subsection{Policy analysis: the role of the relative size of the entrants}

As it has been already mentioned in Section 3, the number of firms in the industry with competitive entry may drop for two reasons: either because the subsidy program induces redistribution of profits from smaller (younger) to larger (more mature) firms or because the subsidy expenditures are financed via distortionary taxation. In order to evaluate how important the former redistribution effect is, this section compares the previously studied outcomes of the subsidy program with the effects of the subsidies generated in a new economy, which differs from the benchmark only in the relative size of entering firms.

More formally, in the latter economy firms have the same production and training technology, and their productivity shocks follow the same Markov process as in the benchmark economy, but the distribution of entrants' productivity shocks $\widehat{G}(s)$ is such that the relative size of entrants in the modified economy is larger than in the the benchmark. In this numerical example, the entrants employ $41 \%$ fewer workers than the incumbent firms do, while in the benchmark economy this difference was as large as $68 \%$. Obviously, the difference in the distribution of entrants' productivity shocks also implies that the long run distribution $\widehat{\mu}_{\lambda}$ differs from $\mu_{\lambda}$. However, the new entry $\operatorname{cost} \eta$ is chosen so that the benchmark equilibrium wages $w_{h}=1.96$ and $w_{l}=1.30$ are also consistent with the free entry equilibrium in the new economy. That is why the corresponding unemployment rates coincide in the two economies in the absence of subsidies.

Figure 5 compares the effects of the targeted employment subsidies for both economies (the results for the benchmark economy are plotted with the solid line). It turns out that in the economy with relatively large entrants the same subsidy rate induces fewer firms to exit. For instance, a $17 \%$ employment subsidy crowds out $18 \%$ of firms in the modified economy as opposed to $28 \%$ in the benchmark economy. Correspondingly, all unemployment rates are lower in the new economy: when the average unemployment rate reaches its minimum of $5 \%$ in the benchmark economy, the average unemployment level in the modified economy becomes equal to $4.6 \% .^{23}$ Notably, the total effect on employment is still positive and significant at quite high subsidy levels, which generate a fall in the average economy's employment in the benchmark economy. ${ }^{24}$

\footnotetext{
${ }^{23}$ It reaches its minimum of $4.4 \%$ at the rate $\theta=0.26$.

${ }^{24}$ Similar patterns are preserved if either the endogenous tax rate or the cost of the subsidy program (measured as a fraction of total labor income) are plotted on the horizontal axis of the graphs on Figure 5. Having a look at such representation might be interesting because these two variables are directly related to the size of the distortionary effect.
} 

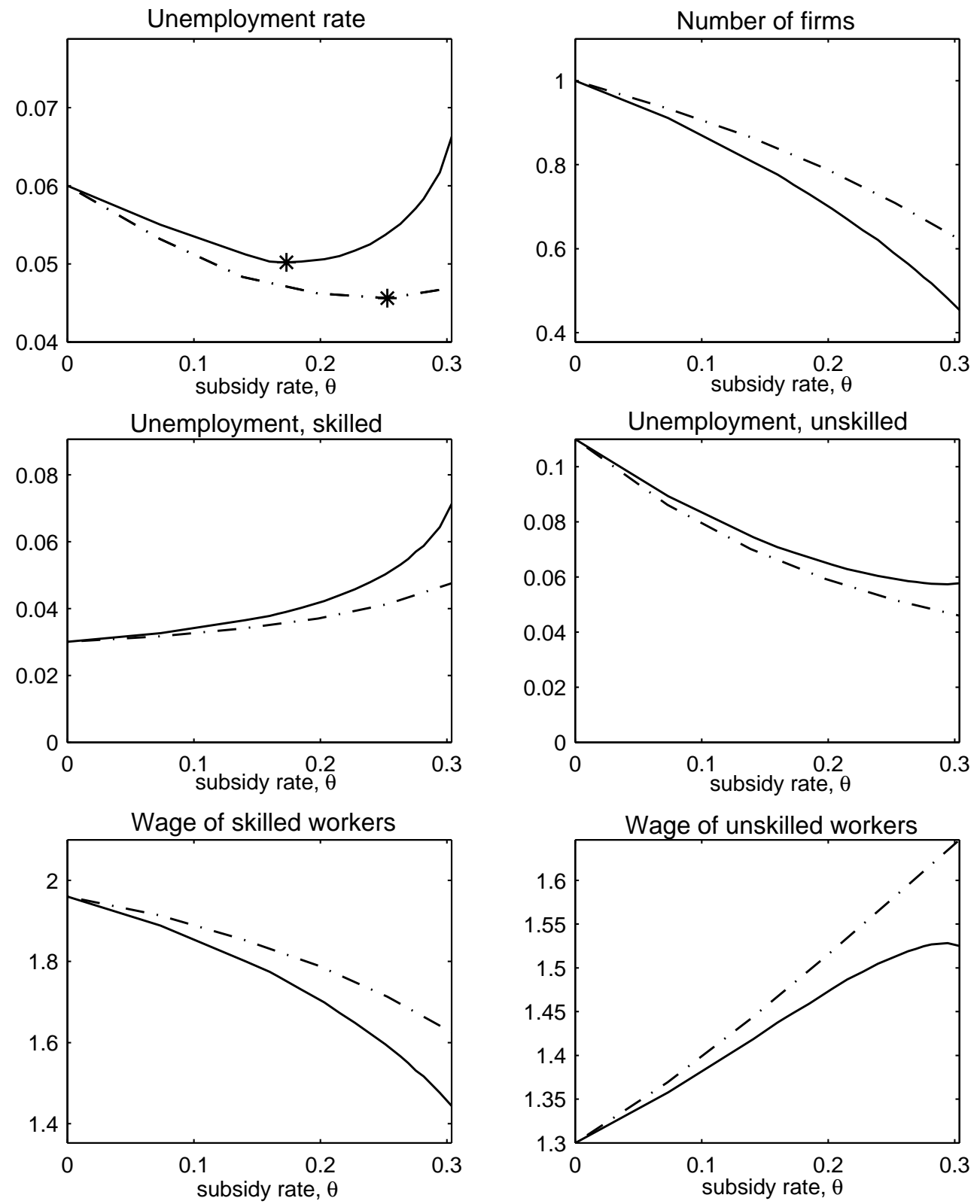

Figure 4: Comparison of the effects of targeted employment subsidies in the economies with small $(-)$ and large $(-\cdot-)$ entrants. 


\section{$5 \quad$ Final Remarks}

Empirical studies document that large firms provide more training per employee and hire more subsidized workers (measured as a fraction of firms' labor force) than small firms do. At the same time, firm dynamics literature provides broad evidence of the positive relationship between firms' size and age. These findings suggest that large and mature firms benefit from the introduction of targeted employment subsidies, while small and young establishments may incur indirect costs. The theoretical analysis in this paper argues that such redistribution of profit from young to mature firms might decrease the value of entrants, discourage start ups and weaken the effects of new government policy. A numerical exercise in the last section illustrates that the resulting exit of firms can even revert the expected policy outcomes.

In particular, if a policymaker believes that the employment subsidy program does not affect the number of operating firms or if he does not take into account the large heterogeneity between young and mature firms observed in the data, he would expect that a $30 \%$ subsidy for hiring unskilled workers should have a positive impact on total employment. However, in the modeled economy, this subsidy rate would actually decrease the total employment level if one accounts for endogeneity of the number of operating firms as well as the realistic differences between young and mature firms. In addition, the simulation exercise presented in this paper shows that the relationship between the economy's employment and subsidy rate is not monotone and that the same subsidy rate would generate more employment as the degree of heterogeneity between young and mature firms increases.

In general, the main argument presented in this work is not specific to the targeted employment subsidy programs, but could be applied to many other policies that are likely to have different impacts on the firms of different ages (firing taxes, start-up subsidies, etc.). Obviously, the general equilibrium effect described in this paper would be important only if a policy is implemented on a large scale (e.g., industry or economy level). For instance, in the numerical example discussed above the targeted group of workers is quite large, constituting about $35 \%$ of the population. If the size of this group were much smaller, no significant effect on total employment would be observed.

A large number of empirical and theoretical studies discuss the sizes of substitution and replacement effects associated with the introduction of various subsidy programs. The goal of these works is to find out whether these programs create incentives for firms to fire their regular workforce and hire instead subsidized workers. Traditionally, 
the replacement effects are evaluated by looking at the individual firms' decisions. This paper describes a replacement mechanism that cannot be traced at the individual firms' level. In response to the introduction of subsidies, an average firm in the industry hires more workers of each type. However, the total employment level of the skilled population may drop due to an endogenous decrease in the number of operating firms. Such aggregate replacement effect is likely to get bigger as the heterogeneity between young and mature firms gets more pronounced. From the econometric point of view, this observation suggests that (i) a structural general equilibrium model would produce a more accurate estimate of the replacement effects than a reduced-form approach and (ii) some measure of heterogeneity between young and mature firms could be an important explanatory variable while estimating the effects of employment subsidy programs. 


\section{References}

Alvarez, F. and M. Veracierto (2000). "Labor Market Policies in an Equilibrium Search Model." NBER Macroeconomics Annual, pp. 265-316.

Bell, B., R. Blundell and J. Reenen (1999). "Getting the Unemployed back to Work: The Role of Targeted Employment Subsidies." The Institute for Fiscal Studies Working Paper Series, No. W99/12.

Bishop, J. and M. Montgomery (1986). "Evidence on Firm Participation in Employment Subsidy Programs." Industrial Relations, Vol. 25, No. 1:56-64.

Blundell, K. and C. Meghir (2001). "Active Labor Market Policy vs Employment Tax Credit: Lessons from Recent UK Reforms." Swedish Economic Policy Review, 8(2): 239-366.

Burtless, G. (1985). "Are Targeted Employment Subsidies Harmful? Evidence From a Wage Voucher Experiment." Industrial and Labor Relations Review, 39, 105-114.

Carling, K. and K. Richardson (2001). "The Relative Efficiency of Labor Market Programs: Swedish Experience from the 1990's." IFAU Working paper, 2001:2.

Calmfors, L., M. Forslund and M. Hemstrom (2001). "Does active labor market policy work? Lessons from the Swedish experiences." Swedish Economic Policy Review, 8(2): 63-124.

Chetty, R. (2003). "A New Method of Estimating Risk Aversion." NBER Working Paper Series, No. 9988.

Davis, S. and J. Haltiwanger (1992). "Gross Job Creation, Gross Job Destruction, and Employment Reallocation." The Quarterly Journal of Economics, 107(3):819-63.

Dunne, T., M. Roberts and L. Samuelson (1988). "Patterns of Firm Entry and Exit in U.S. Manufacturing Industries." RAND Journal of Economics, 19(4):495-515. 
Dunne, T., M. Roberts and L. Samuelson (1989). "The Growth and Failure of U.S. Manufacturing Plants." Quarterly Journal of Economics, 104 (1989), 671-698.

Frazis, H., M. Gittleman, M. Horrigan and Mary Joyce (1998). "Results from the 1995 Survey of Employer-Provided Training." Monthly Labor Review Online, June 1998, Vol. 121, No. 6.

Hopenhayn, H. (1992). "Entry, Exit, and Firm Dynamics in Long Run Equilibrium." Econometrica, 60 (5), 1127-1150.

Hopenhayn, H. and R. Rogerson (1993). "Job Turnover and Policy Evaluation: A General Equilibrium Analysis." Journal of Political Economy, 101(5), 915-938.

Hui, W. and P. Trivedi (1986). "Duration Dependence, Targeted Employment Subsidies And Unemployment Benefits." Journal of Public Economics, 31, 105-129.

Kaldor, N. (1936). "Wage Subsidies as a Remedy for Unemployment." Journal of Political Economy, 44.

Katz, L. (1996). "Wage Subsidies for the Disadvantaged." NBER Working Paper Series, No. 5679.

Kambourov, G. and I. Manovskii (2002). "Rising Occupational and Industry Mobility in the US: Evidence from the 1968-1993 PSID." Unpublished manuscript.

Katz, L. (1996). "Wage Subsidies for the Disadvantaged." NBER Working Paper Series, No. 5679.

Martin, J., and D. Grubb (2001). "What Works And for Whom: A Review of OECD Countries' Experience With Active Labor Market Policies." Swedish Economic Policy Review, 8(2): 11-60.

Mortensen, D. and C. Pissarides (1998). "Taxes, Subsidies and Equilibrium Labor Market Outcomes." CEPR Discussion Paper Series, No. 2989. 
Nickell, S., and B. Bell (1996). "Changes in the Distribution of Wages and Unemployment in OECD Countries." American Economic Review 86(2): 302-308.

Orszag, M. and D.. Snower (2002). "Unemployment Vouchers versus Low-Wage Subsidies." IZA Discussion Paper Series, No. 537.

Phelps, E. (1994). "Low-Wage Employment Subsidies Versus The Welfare State." American Economic Review, 84(2), 54-58.

Richardson, J. (1997). "Can Active Labor Market Policy work? Some Theoretical Considerations." Center for Economic Performance Discussion Paper Series, No. 331.

Shapiro, C. and J. Stiglitz (1984). "Equilibrium Unemployment as a Worker Discipline Device." American Economic Review, 74(3): 433-444.

Sianesi, B. (2001). "Differential Effects of Swedish Active Labor Market Programmes for Unemployed Adults During the 1990s." IFAU Working Paper Series

Veracierto, M. (2000). "Employment Flows, Capital Mobility, and Policy Analysis." Federal Reserve Bank of Chicago Working Paper Series, No. 2000-05. 


\section{Appendix}

Proof of Lemma 1. Rewrite (2) as a function of $n_{l}$ and $l=n_{h}+n_{l}$ :

$$
\pi^{*}\left(s ; w_{h}, w_{l}\right)=\max _{l, n_{l}}\left\{s f(l)-w_{h}\left(l-n_{l}\right)-w_{l} n_{l}-c\left(n_{l}, l-n_{l}\right)\right\}
$$

To save on notations, denote the expression in the brackets on the right hand side of (20) by $\pi\left(l, n_{l}\right)$. Then, if $c\left(n_{l}, l-n_{l}\right)$ is given by (1), the first order conditions for the profit maximization problem $(20)$ can be written as

$$
\begin{aligned}
(l): & \pi_{1}\left(l, n_{l}\right)=s f^{\prime}(l)-w_{h}+(1+\gamma) \frac{n^{1+\gamma}}{A^{1+\gamma}\left(l-n_{l}\right)^{2+\gamma}}=0, \\
\left(n_{l}\right): & \pi_{2}\left(l, n_{l}\right)=w_{h}-w_{l}-(1+\gamma) \frac{n^{\gamma} l}{A^{1+\gamma}\left(l-n_{l}\right)^{2+\gamma}}=0 .
\end{aligned}
$$

The second equation in (21) implies that

$$
l=\frac{1+\gamma}{\left(w_{h}-w_{l}\right) A^{1+\gamma}} \frac{\left(n_{l} / l\right)^{\gamma}}{\left(1-n_{l} / l\right)^{2+\gamma}} .
$$

The right hand side of the above equation is increasing in $n_{l} / l$, so firm size and fraction of unskilled workers among its employees are positively related.

Substituting (22) into the first equation in (21) results in

$$
s f^{\prime}(l)=w_{h}-\left(w_{h}-w_{l}\right) \frac{n_{l}}{l} .
$$

Equations (22) and (23) form a system of equations with two unknowns, $l$ and $x=$ $\frac{n_{l}}{l} \in[0,1]$. Each of these two equations implicitly defines an increasing relationship between $l$ and $x$. Denote these two relationships correspondingly by $l_{1}(x)$ and $l_{2}(x)$. Since $l_{1}(0)<l_{2}(0)$ and $\lim _{x \rightarrow 1} l_{1}(x)>l_{2}(1)$, the system of equations has at least one solution. In order to establish its uniqueness, it is enough to show that $l_{1}^{\prime}(x)>l_{2}^{\prime}(x)$ for all $x \in(0,1)$. Differentiating (22) and (23) with respect to $x$ implies that

$$
\begin{aligned}
& l_{1}^{\prime}(x)=l_{1}(x)\left(2+\frac{\gamma}{x}\right) /(1-x), \\
& l_{2}^{\prime}(x)=-\left(w_{h}-w_{l}\right) /\left(s f^{\prime \prime}(l)\right) .
\end{aligned}
$$


Thus, $l_{1}^{\prime}(x)>l_{2}^{\prime}(x)$ if and only if

$$
1-x+\frac{2 x+\gamma}{x} \frac{s f^{\prime \prime}(l) l}{w_{h}-w_{l}}<0
$$

As $x \rightarrow 0$ or $x \rightarrow 1$, the above inequality holds for any concave function $f(l)$. One way to ensure that the inequality (25) also holds for all $x \in(0,1)$ is to establish monotonicity of the expression in the left hand side. In a general case, a certain relationship between $\gamma$ and $f^{(3)}(l) l / f^{(2)}(l)$ could be imposed. However, a simpler condition can be derived for $f(l)=l^{\alpha}$, for which

$$
\frac{s f^{\prime \prime}(l) l}{w_{h}-w_{l}}=\frac{s(\alpha-1) f^{\prime}(l)}{w_{h}-w_{l}}=(1-\alpha)\left(x-\frac{w_{h}}{w_{h}-w_{l}}\right)
$$

where the last equality is obtained using (23). Substituting (26) in (25) and differentiating it with respect to $x$ implies that the right hand side of (25) is strictly increasing over $(0,1)$ if

$$
\gamma \geq \frac{w_{h}-w_{l}}{w_{h}} \frac{|2 \alpha-1|}{1-\alpha}
$$

suggesting that the curvature of the training cost $c\left(l, l-n_{l}\right)$ must be sufficiently high in order to ensure the uniqueness of the solution to (22) and (23).

The next step is to verify that the second order conditions are satisfied. The second order partial derivatives of $\pi\left(l, n_{l}\right)$ are given by

$$
\begin{aligned}
& \pi_{11}\left(l, n_{l}\right)=s f^{\prime \prime}(l)-(2+\gamma) \frac{n_{l}}{l-n_{l}} \frac{w_{h}-w_{l}}{l}<0, \\
& \pi_{22}\left(l, n_{l}\right)=-\left(w_{h}-w_{l}\right) \frac{1}{n_{l}} \frac{\gamma l+2 n_{l}}{l-n_{l}} \\
& \pi_{12}\left(l, n_{l}\right)=\left(w_{h}-w_{l}\right) \frac{1}{l} \frac{n_{l}+(1+\gamma) l}{l-n_{l}} .
\end{aligned}
$$

The solution to (22) and (23) is a local maximum if $\pi_{11}\left(l, n_{l}\right) \pi_{22}\left(l, n_{l}\right)-\left(\pi_{12}\left(l, n_{l}\right)\right)^{2} \geq 0$. Substituting (27) into the left hand side of the latter inequality, it is easy to derive that the second order conditions are satisfied if and only if the inequality (25) holds.

Therefore, if $f(l)=l^{\alpha}$ and $\gamma \geq \frac{w_{h}-w_{l}}{w_{h}} \frac{|2 \alpha-1|}{1-\alpha}$, the profit maximization problem (20) has a unique interior solution $\left(n_{l}^{*}\left(s ; w_{h}, w_{l}\right), l^{*}\left(s ; w_{h}, w_{l}\right)\right)$. This proves (i) of Lemma 1.

In addition, (22) and (23) imply that $\partial l^{*}\left(s ; w_{h}, w_{l}\right) / \partial s>0$, which, combined with the positive relationship between $l$ and $n_{l} / l$ derived from (22), proves (ii) of Lemma 1 .

In order to show that (iii) holds, it is enough to prove that $\frac{\partial^{2} p i^{*}\left(s ; w_{h}, w_{l}\right)}{\partial w_{l} \partial s}<0$ (since 
$\left.\frac{\partial \pi^{*}\left(s ; w_{h}, w_{l}\right)}{\partial w_{l}}<0\right)$. Substituting $(23)$ into the expression for profit implies that

$$
\pi^{*}\left(s ; w_{h}, w_{l}\right)=s f(l)-s l f^{\prime}(l)-c\left(n_{l}, l\right) .
$$

Differentiating it with respect to $s$ we obtain that

$$
\frac{\partial \pi^{*}\left(s ; w_{h}, w_{l}\right)}{\partial s}=f(l)-l f^{\prime}(l)-s l f^{\prime \prime}(l) \frac{\partial l}{\partial s}-\left(w_{h}-w_{l}\right) \frac{\partial n_{l}}{\partial s}-\left(s f^{\prime}(l)-w_{h}\right) \frac{\partial l}{\partial s} .
$$

Equation (23) allows us to express $\partial n_{l} / \partial s$ as a function of $l$ and $\partial l / \partial s$ :

$$
\left(w_{h}-w_{l}\right) \frac{\partial n_{l}}{\partial s}=w_{h} \frac{\partial l}{\partial s}-l f^{\prime}(l)-s\left(f^{\prime}(l)+f^{\prime \prime}(l) l\right) \frac{\partial l}{\partial s} .
$$

Substituting the above expression into (28) implies that $\frac{\partial \pi^{*}\left(s ; w_{h}, w_{l}\right)}{\partial s}=f(l)$. Then $\frac{\partial^{2} \pi^{*}\left(s ; w_{h}, w_{l}\right)}{\partial s \partial w_{l}}=f^{\prime}(l) \frac{\partial l}{\partial w_{l}}$, which is less than zero if and only if $\frac{\partial l}{\partial w_{l}}<0$.

In order to determine the sign of $\frac{\partial l}{\partial w_{l}}$, differentiate $(22)$ and $(23)$ with respect to $w_{l}$ :

$$
\begin{aligned}
& s f^{\prime \prime}(l) \frac{\partial l}{\partial w_{l}}+\left(w_{h}-w_{l}\right) \frac{\partial x}{\partial w_{l}}=x \\
& \frac{1}{l} \frac{\partial l}{\partial w_{l}}-\frac{2 x+\gamma}{x(1-x)} \frac{\partial x}{\partial w_{l}}=\frac{1}{w_{h}-w_{l}} .
\end{aligned}
$$

Solving the above system of equations we obtain

$$
\begin{aligned}
& \frac{\partial l}{\partial w_{l}}\left(1-x+\frac{2 x+\gamma}{x} \frac{s f^{\prime \prime}(l) l}{w_{h}-w_{l}}\right)=\frac{1}{w_{h}-w_{l}}\left(1+\frac{2 x+\gamma}{1-x}\right) \\
& \frac{\partial x}{\partial w_{l}}=\frac{x}{w_{h}-w_{l}}-\frac{s f^{\prime \prime}(l) l}{w_{h}-w_{l}} \frac{\partial l}{\partial w_{l}}
\end{aligned}
$$

Correspondingly, $\frac{\partial l}{\partial w_{l}}<0$ if and only if the inequality (25) holds. Therefore, the condition $\gamma \geq \frac{w_{h}-w_{l}}{w_{h}} \frac{|2 \alpha-1|}{1-\alpha}$ stipulates that $\partial^{2} \pi^{*}\left(s ; w_{h}, w_{l}\right) / \partial w_{l} \partial s<0$, which proves (iii) of Lemma 1.

Finally, it is straightforward to see that $\lim _{s \rightarrow 0} \frac{\partial^{2} \pi^{*}\left(s ; w_{h}, w_{l}\right)}{\partial w_{l} \partial s}=0$, which implies (iv) of Lemma 1.

$$
\text { Q.E.D }
$$

Proof of Lemma 2. By the Blackwell Sufficient Condition, the functional operator in the right hand side of the Bellman equation (4) is a contraction and thus, by 
Contraction Mapping Theorem, (4) has a unique solution $V\left(s ; w_{h}, w_{l}\right)$. A standard recursive argument, together with Assumption 1 implies that $V\left(s ; w_{h}, w_{l}\right)$ is a continuous and increasing function in $s$.

Since $s=0$ is an absorbing state, $\lim _{s \rightarrow 0} \int V\left(s^{\prime} ; w_{h}, w_{l}\right) Q\left(s, d s^{\prime}\right)=V\left(0 ; w_{h}, w_{l}\right)$. Therefore, $V\left(0 ; w_{h}, w_{l}\right)=\pi^{*}\left(0 ; w_{h}, w_{l}\right)+\frac{1}{1+r} \max \left\{0, V\left(0 ; w_{h}, w_{l}\right)\right\}$, which implies that $V\left(0 ; w_{h}, w_{l}\right)=0$. By monotonicity of $V\left(s ; w_{h}, w_{l}\right)$ in its first argument,

$$
V\left(s ; w_{h}, w_{l}\right) \geq \pi^{*}\left(s ; w_{h}, w_{l}\right)+0>0
$$

for all $s>0$. This completes the proof of (i) of Lemma 2 .

Note that $\int V\left(s^{\prime} ; w_{h}, w_{l}\right) Q\left(s, d s^{\prime}\right)>0$ for all $s>0$, thus for any positive $s$ (4) can be rewritten as

$$
V\left(s ; w_{h}, w_{l}\right)=\pi^{*}\left(s ; w_{h}, w_{l}\right)+\frac{1}{1+r} \int V\left(s^{\prime} ; w_{h}, w_{l}\right) Q\left(s, d s^{\prime}\right) .
$$

Differentiating (31) with respect to $w_{l}$, applying monotonicity of $Q(s, S)$ and using (iii) of Lemma 1, verifies (ii) of Lemma 2 in a straightforward way. In addition, from Assumptions 1 and 2, combined with $\lim _{s \rightarrow 0} \frac{\partial^{2} \pi^{*}\left(s ; w_{h}, w_{l}\right)}{\partial s \partial w_{l}}=0$ it follows that (iii) of Lemma 2 holds.

Finally, it is easy to see that the value function $V_{\tau}\left(s ; w_{h}, w_{l}\right)=(1-\tau) V\left(s ; w_{h}, w_{l}\right)$ solves the Bellman equation (5). Thus

$$
\lim _{s \rightarrow 0} \frac{V_{\tau}\left(s ; w_{h}, w_{l}-\Delta\right)}{V\left(s ; w_{h}, w_{l}\right)}=(1-\tau) \lim _{s \rightarrow 0} \frac{V\left(s ; w_{h}, w_{l}-\Delta\right)}{V\left(s ; w_{h}, w_{l}\right)}=1-\tau<1 .
$$

Employing continuity and monotonicity of both $V\left(s ; w_{h}, w_{l}\right)$ and $V_{\tau}\left(s ; w_{h}, w_{l}\right)$ allows us to conclude that (iv) of Lemma 2 holds.

$$
\text { Q.E.D }
$$

Proof of Lemma 4. Since $w_{l}$ and $w_{h}$ have no impact on the shape of the stationary distribution $\mu_{\lambda}$, it is enough to show that similar properties hold for the individual firms' hiring policies. The structure in the proof is reminiscent with the one used in the proof of (iii) in the first Lemma: differentiating (22) and (23) with respect to $w_{h}$ (or $w_{l}$ ) produces the system of two equations with two unknown partial derivatives. Solving this system allows to determine the derivatives' signs. 
First, note that

$$
\frac{\partial n_{l}}{\partial w_{l}}=\frac{\partial x}{\partial w_{l}} l+\frac{\partial l}{\partial w_{l}} x
$$

where $x=n_{l} / l$. Equations (22) and (23) have been already differentiated with respect to $w_{l}$ in (30). Substituting them into (32) implies that

$$
\frac{\partial n_{l}}{\partial w_{l}}=\frac{l}{w_{h}-w_{l}}\left[\frac{1+x+\gamma}{1-x+\frac{2 x+\gamma}{x} \frac{s f^{\prime \prime}(l) l}{w_{h}-w_{l}}}\left(x-\frac{s f^{\prime \prime}(l) l}{w_{h}-w_{l}}\right)+x\right] .
$$

Rearranging the terms on the right hand side of the above expression and using inequality (25), which has been established earlier as a necessary condition for $\frac{\partial l}{\partial w_{l}}<0$, one easily derives that $\frac{\partial n_{l}}{\partial w_{l}}<0$ if and only if

$$
2 x+\gamma x-\frac{s f^{\prime \prime}(l) l}{w_{h}-w_{l}}>0 .
$$

Concavity of $f(l)$ implies that the above inequality is always true. Thus $\frac{\partial n_{l}}{\partial w_{l}}<0$ holds for every operating firm, and a similar property is satisfied for the aggregate demand, $\frac{\partial N_{l}^{D}\left(w_{h}, w_{l}, \lambda\right)}{\partial w_{l}}<0$.

In order to prove the second part of the statement (i) of Lemma 4, differentiate (22) and (23) with respect to $w_{h}$ :

$$
\begin{aligned}
& \frac{\partial x}{\partial w_{h}}=\frac{1-x}{w_{h}-w_{l}}-\frac{s f^{\prime \prime}(l)}{w_{h}-w_{l}} \frac{\partial l}{\partial w_{h}} \\
& \frac{\gamma+2 x}{x(1-x)} \frac{\partial x}{\partial w_{h}}=\frac{1}{w_{h}-w_{l}}+\frac{1}{l} \frac{\partial l}{\partial w_{h}} .
\end{aligned}
$$

This allows us to express $\frac{\partial n_{h}}{\partial w_{h}}$ as

$$
\frac{\partial n_{h}}{\partial w_{h}}=\frac{l(1-x)}{w_{h}-w_{l}} \frac{(\gamma+x)\left(1-x+\frac{s f^{\prime \prime}(l) l}{w_{h}-w_{l}}\right)-x\left(1-x+\frac{\gamma+2 x}{x} \frac{s f^{\prime \prime}(l) l}{w_{h}-w_{l}}\right)}{1-x+\frac{\gamma+2 x}{x} \frac{s f^{\prime \prime}(l) l}{w_{h}-w_{l}}}
$$

As it has been shown earlier, the denominator of the right hand side is negative since $\frac{\partial l}{\partial w_{l}}<0$. Thus $\frac{\partial n_{l}}{\partial w_{l}}$ is negative if and only if the numerator on the right hand side is positive. One can easily verify that this is true by rearranging the terms of the nominator and showing that it collapses to a positive expression, $\gamma(1-x)-x \frac{s f^{\prime \prime}(l) l}{w_{h}-w_{l}}$. This completes the proof of (i) of Lemma 3.

Finally, $\frac{\partial n_{h}}{\partial w_{l}}=\frac{\partial l}{\partial w_{l}}(1-x)-\frac{\partial x}{\partial w_{l}} l$. Substitute into this equation the expressions for 
$\partial l / \partial w_{l}$ and $\partial x / \partial w_{l}$ that solve (30). This results in

$$
\frac{\partial n_{h}}{\partial w_{l}}=\frac{l(1-x)}{w_{h}-w_{l}}\left(1+\frac{2 x+\gamma}{1-x}\right) \frac{1-x+\frac{s f^{\prime \prime}(l) l}{w_{h}-w_{l}}}{1-x+\frac{2 x+\gamma}{x} \frac{s f^{\prime \prime}(l) l}{w_{h}-w_{l}}}-\frac{x l}{w_{h}-w_{l}}
$$

Rearranging the terms in the above equation and using the inequality (25) we conclude that $\partial n_{h} / \partial w_{l}<0$ if and only if

$$
1+\gamma+\frac{s f^{\prime \prime}(l) l}{w_{h}-w_{l}}>0
$$

Substitute (26) into the above inequality to obtain that it holds for every $x$ if $\frac{w_{l}}{w_{h}}<$ $1-\frac{1-\alpha}{1+\gamma}$. Therefore, (ii) of Lemma 3 is also verified.

Q.E.D

Proof of Proposition 1 is straightforward and is summarized in the discussion following the proposition. 
(c) Galina Vereshchagina, 2005

All rights reserved. No part of this publication may be reproduced, stored in a retrieval system or transmitted in any form or by any means, electronic, mechanical or photocopying, recording, or otherwise without the prior permission of the publisher.

Published by

Charles University in Prague, Center for Economic Research and Graduate Education (CERGE) and

Economics Institute (EI), Academy of Sciences of the Czech Republic

CERGE-EI, Politických vězňů 7, 11121 Prague 1, tel.: +420 224005 153, Czech Republic.

Printed by CERGE-EI, Prague

Subscription: CERGE-EI homepage: http://www.cerge-ei.cz

Editors: Directors of CERGE and EI

Managing editors: Deputy Directors for Research of CERGE and EI

ISSN 1211-3298

ISBN 80-7343-061-4 (Univerzita Karlova v Praze, CERGE)

ISBN 80-7344-050-4 (Národohospodářský ústav AV ČR, Praha) 
CERGE-EI

P.O.BOX 882

Politických vězňů 7

11121 Praha 1

Czech Republic http://www.cerge-ei.cz 